

\section{DISCLAIMER}

This report was prepared as an account of work sponsored by an agency of the United States Government. Neither the United States Government nor any agency Thereof, nor any of their employees, makes any warranty, express or implied, or assumes any legal liability or responsibility for the accuracy, completeness, or usefulness of any information, apparatus, product, or process disclosed, or represents that its use would not infringe privately owned rights. Reference herein to any specific commercial product, process, or service by trade name, trademark, manufacturer, or otherwise does not necessarily constitute or imply its endorsement, recommendation, or favoring by the United States Government or any agency thereof. The views and opinions of authors expressed herein do not necessarily state or reflect those of the United States Government or any agency thereof. 


\section{DISCLAIMER}

Portions of this document may be illegible in electronic image products. Images are produced from the best available original document. 


\subsection{0 \\ PRICE \\ Available from the \\ Office of Technical Services \\ U.S. Department of Commerce \\ Washington 25, D. C.}

\section{LEGAL NOTICE}

This report was prepared as an account of Government sponsored work. Neither the United States, nor the Commission, nor any person acting on behalf of the Commission:

A. Makes any warranty or representation, express or implied, with respect to the accuracy, completeness, or usefulness of the information contained in this report, or that the use of any information, apparatus, method, or process disclosed in this report may not infringe privately owned rights; or

B. Assumes any liabilities with respect to the use of, or for damages resulting from the use of any information, apparatus, method, or process disclosed in this report.

As used in the above, "person acting on behalf of the Commission" includes any employee or contractor of the Commission, or employee of such contractor, to the extent that such employee or contractor of the Commission, or employee of such contractor prepares, disseminates, or provides access to, any information pursuant to his employment or contract with the Commission, or his employment with such contractor. 


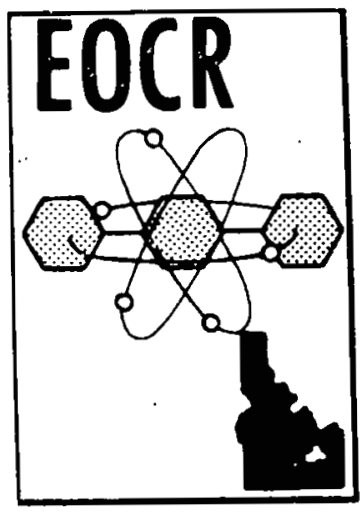

IDO-16909

AEC Research and Development Report

Reactor Technology

OTT PRICRS

TID -4500 (21st Ed.)

Issued: August 30, 1963

IA. $3.00 ; \mathrm{MN}: 65$

LEGA L NOTICE

This report was prepared as an account of Government sponsored work. Nelther the United States, nor the Commission, nor any person acting on behalf of the Commission:

A. Makes any warranty or representation, expressed or implied, with respect to the accuracy, completeness, or usefulness of the information contained in this report, or that the use of any information, apparatus, method, or process disclosed in this report may not infringe

B. Assumes any liabslities with respect to the use of, or for damages resulting from the use of any information, apparatus, method, or process disclosed in this report.

As used in the above, "perkon acting on behalf of the Commission" Includes any employee or contractor of the Commission, or employee of such contractor, to the extent that such employee or contractor of the Commission, or employee of such contractor preparca,

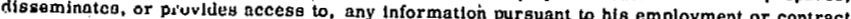
with the Commission, or his employment with auch contractor.

CHARACTERIZATION OF HIGH-BOILING PRODUCTS FROM IRRADIATED BIPHENYL AND TERPHENYLS

by

P. W. Solomon, P. S. Hudson, and A. J. Moffat

'RELEASED TOK UNIOUSCERET

PHILLIPS

IA WUCLEAR SCIMER ABSTRACTS

\section{PETROLEUM}

COMPANY

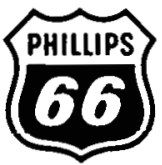

Research and Development Department

Bartlesville, Oklahoma

Contract AT(10-1) -1080

Idaho Operations Office

U. S. ATTOMIC ENERGY COMMISSION 
THIS PAGE

\section{WAS INTENTIONALLY LEFT BLANK}




\title{
CHARACTERIZATION OF HIGH-BOILING \\ PRODUCTS FROM IRRADIATED BIPHENYL AND TERPHENYLS
}

\author{
SUMMARY
}

Characterization work on the high-boiling components formed by pyrolysis and/or radiolysis of polyphenyls has been performed. Distillation and solvent fractionation have shown that considerable material above 200 molecular weight was present. High-boiler residue was more easily fractionated (solvent precipitation) than the parent coolant from which the residue was obtained. During radiolysis, weight average molecular weight changed more than number average and was more sensitive to higher-molecular-weight molecules. A sublimation/ number average molecular weight method was developed for the determination of weight average molecular weight. Evidence-for fused-ring structure, alkyl side groups, aliphatic unsaturation (possibly alkenyl groups), and polyphenyl structure was found.

An organic, benzene-insoluble material was present in irradiated highboiling products. The quantity of this material greatly increased by heating the high boiler in vacuo to $380^{\circ} \mathrm{C}$. This additionally created insoluble material showed a structure similar to the total high-boiling products. However, chlorine became concentrated in the benzene insoluble fraction and the highest-molecularweight soluble fractions. Before heating, the chlorine was distributed throughout all the fractions. A benzene solution of coolant or high boiler formed insoluble film on glass surfaces. The rate of film formation was studied in colorimeter tubes and high-molecular-weight fractions gave more film than low-molecularweight fractions. Benzene insoluble sludge was centrifuged from benzene solutions of coolant or high boiler. Both film and sludge may be correlated with fouling tendencies in a reactor and serve as laboratory tests for coolant cleanliness.

The oxidizing power of $\mathrm{KMnO}_{4}$ is considerably reduced by performing the oxidation in pyridine solvent without inorganic base. This system was used to study the susceptibility of the irradiated high-boiler products to oxidation. A large amount of low-boiling acids was obtained which indicated chain scission of high-molecular-weight polymers. Reaction of the high-boiling products with sulfuric acid, nitric acid, and bromine, and hydrogenation of the products contributed to the understanding of the structures present. 


\section{CONTENTS}

SUMMARY $\ldots \ldots \ldots \ldots \ldots \ldots \ldots \ldots \ldots \ldots \ldots \ldots \ldots \ldots \ldots \ldots \ldots \ldots$

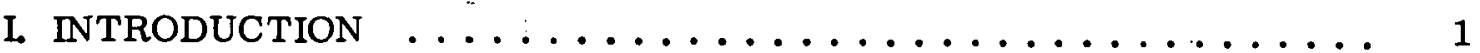

II. EXPERIMENTAL, RESULTS, AND DISCUSSION $\ldots \ldots \ldots \ldots$

1. DISTILLATION OF OMRE HIGH BOILER $\ldots \ldots \ldots \ldots \ldots \ldots$

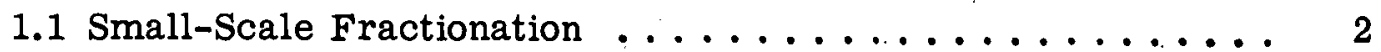

1.2 Larger-Scale Flash Distillation . . . . . . . . . . . . . . 4

2. SOLVENT FRACTIONATION OF OMRE HB ........... 4

2.1 Methanol/Benzene System ................... 4

$2.2 \mathrm{~N}$-Penthane/Benzene System ..................... 4

2.3 Cyclohexane/Benzene System $\ldots \ldots \ldots . \ldots . \ldots . \ldots 9$

3. CHARACTERIZATION OF OMRE HB BY

WEIGHT AVERAGE MOLECULAR WEIGHT $\ldots \ldots \ldots \ldots$

4. CHARACTERIZATION OF BENZENE-

INSOLUBLE MATERIAL PRESENT IN OMRE HB $\ldots . . . . . .13$

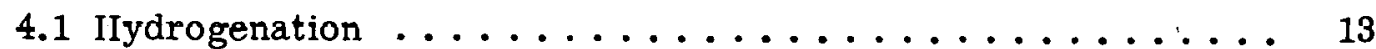

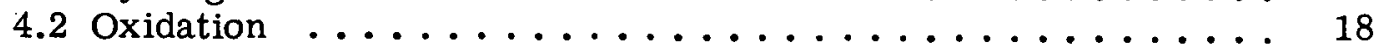

4.3 Reactions with $\mathrm{H}_{2} \mathrm{SO}_{4}, \mathrm{HNO}_{3}$, and $\mathrm{Br}_{2} \ldots \ldots \ldots \ldots$

5. OXIDATION OF OMRE HB ....... . . . . . . . . 23

$5.1 \mathrm{Na}_{2} \mathrm{Cr}_{2} \mathrm{O}_{7} / \mathrm{H}_{2} \mathrm{O} \ldots \ldots \ldots \ldots \ldots \ldots \ldots \ldots \ldots \ldots \ldots \ldots . \ldots \ldots \ldots . \ldots \ldots$

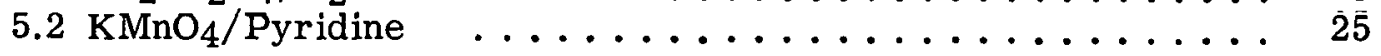

6. FILMS DEPOSITED FROM BENZENE

SOLUTION OF OMRE HB AND IRRADIATED

COOLANT FROM OMRE HB REACTOR (CORE 2 COOLANT . . . 27

7. COMPOSITION OF HIGH BOILERS FORMED

FROM IRRADIATED BIPHENYL AND O-TERPHENYL . . . . . . 36

8. SPECULATIONS ON UNSATURATED SPECIES

PRESENT IN IRRADIATED TERPHENYLS ........... 37

III. CONCLUSIONS $\ldots \ldots \ldots \ldots \ldots \ldots \ldots \ldots \ldots \ldots \ldots \ldots \ldots \ldots$

IV. REFERENCES .......................... 40 


\section{FIGURES}

1a. Infrared spectra of fractions isolated from OMRE high boiler . . . . 7

1b. Infrared spectra of fractions isolated from OMRE high boiler . . . . 8

2. Molecular weight profile of high boiler ............... 11

3. $\log$ residue vs $\log \overline{\mathrm{M}} \mathrm{n} \ldots \ldots \ldots \ldots \ldots \ldots \ldots \ldots$

4. Infrared spectrum of benzene-insoluble and boiling-tetralin-soluble hydrogenated BIM ........... 14

5a. Infrared spectra of benzene-soluble hydrogenated BIM fractions $\ldots$. 17

5 b. Infrared spectra of benzene-soluble hydrogenated BIM fractions ... 18

6. Infrared spectrum of ozonized BIM ................. 19

7a. Infrared spectra of $\mathrm{H}_{2} \mathrm{SO}_{4}, \mathrm{HNO}_{3}, \mathrm{H}_{2} \mathrm{SO}_{4} / \mathrm{HNO}_{3}$ or $\mathrm{Br}_{2}$-treated BIM . . 20

7b. Infrared spectra of $\mathrm{H}_{2} \mathrm{SO}_{4}, \mathrm{HNO}_{3}, \mathrm{H}_{2} \mathrm{SO}_{4} / \mathrm{HNO}_{3}$ or $\mathrm{Br}_{2}$-treated BIM . . 21

8. Infrared spectra of $\mathrm{H}_{2} \mathrm{SO}_{4}$ and $\mathrm{H}_{2} \mathrm{SO}_{4} / \mathrm{HNO}_{3}$-treated m-terphenyl $\ldots .22$

9. Infrared spectra of $\mathrm{Na}_{2} \mathrm{Cr}_{2} \mathrm{O}_{7}$-oxidized OMRE HB and $\mathrm{Cr}_{2} \mathrm{O}_{3} \ldots \ldots .24$

10. Typical infrared spectrum of acids recovered from $\mathrm{KMnO}_{4} /$ pyridine oxidation of OMRE HB or treated OMRE HB or BIM . . . . . . 29

11a. Infrared spectra of film and sludge deposits from benzene solutions of OMRE HB and Core 2 coolant . . . . . . . . 31

11b. Infrared spectra of film and sludge deposits from benzene solutions of OMRE HB and Core 2 coolant $\ldots \ldots \ldots \ldots \ldots$

12. Optical density of film vs time (data from Table I) . . . . . . . . . . 34

13. Film formation on glass from benzene solution of Core 2 coolant (data from Table I) . . . . . . . . . 35

14. Acetylenic compounds from terphenyls ............... 38

\section{TABLES}

I. Analysis of OMRE High Boiler $\ldots \ldots \ldots \ldots \ldots \ldots$

IL Fractionation of OMRE HB .................. 3

III. C/H Ratio for Polyphenyls .................... 3 
IV. Distillation of OMRE HB ................... 4

V. Solvent Fractionation of OMRE HB with Benzene/Methanol $\ldots \ldots \quad 5$

VI. Solvent Fractionation of OMRE HB with Benzene/N-Pentane $\ldots \ldots \quad 5$

VII. Solvent Fractionation of Pot Residue from Distilled OMRE HB with Benzene/N-Pentane ......... 6

VIII. Analysis of Benzene Insoluble OMRE HB from Cyclohexane/Benzene Solvent Fractionation $\ldots . . \ldots . . .9$

IX. High-Boiler Molecular Weights .................. 13

X. Benzene-Soluble Hydrogenated BIM . . . . . . . . . . . . . 15

XI Products from Hydrogenated BIM ................. 16

XII. Treatment of BIM with $\mathrm{H}_{2} \mathrm{SO}_{4}, \mathrm{HNO}_{3}$, and $\mathrm{Br}_{2} \ldots \ldots \ldots \ldots$

XIIL Empirical Formulae of Products from Reaction of $\mathrm{H}_{2} \mathrm{SO}_{4}, \mathrm{HNO}_{3}$, and $\mathrm{Br}_{2}$ with BIM ......... 23

XIV. Oxidation of Organic Compounds with $\mathrm{KMnO}_{4} /$ Pyridine System . . 26

XV. Acids Obtained by $\mathrm{KMnO}_{4} /$ Pyridine Oxidation of OMRE HB and Treated OMRE HB . . . . . . . . . 28

XVL Characterization of Acids Obtained from $\mathrm{KMnO}_{4} /$ Pyrinine-Oxidized OMrE IID ............. . $2 y$

XVIL Benzene Solution Film Test on OMRE HB and Core 2 Coolant . . . 30

XVIIL. Analysis of F'ilms and Insoluble Sludge Deposited from Benzene Solutions of OMRE HB and Core 2 Coolant . . . . . 31

XIX̃. Optical Density of Film from Benzene for Various Fractions of OMRE HB . . . . . . . . . 33

XX. Optical Density of Film from Benzene Solution of Core 2 Coolunt ............... 34

XXI Centrifugation of Core 2 Coolant in Benzene . . . . . . . . . 35

XxII. Analysis of Distilled Cuts from

Electron-Irradiated Biphenyl and O-terphenyl .......... 36

XXIII. Comparison of Properties of OMRE HB and Poly(phenylacetylene) . 38 


\section{CHARACTERIZATION OF HIGH-BOILING \\ PRODUCTS FROM IRRADIATED BIPHENYL AND TERPHENYLS}

\section{INTRODUCTION.}

Radiolysis of benzene, biphenyl, and the terphenyls results in the production of "high-boiler" products as well as hydrogen and small amounts of hydrocarbon products boiling below the parent starting materials.

Biphenyl/terphenyl mixtures are used as moderator-coolants in atomic reactors. Since the high boilers are the major radiolytic product, their analys is may contribute to understanding coolant decomposition and lead to improved coolants. In addition, the high boiler may contain components responsible for fuel element fouling in the OMRE.

A number of studies have been made on identification of gaseous products and "low boilers" (those compounds boiling below the terphenyls) [1-9]. Practically all work concerning "high boilers" has been confined to simply determining the quantity of material distilling above the terpenyls [1]. An examination of the products from atomic reactor irradiation of biphenyl/ terphenyl mixtures by high mass spectrometric techniques [7] shows "polymerization".-type products predominate; for example, terphenyls yield ( $\left.{ }_{3}\right) \mathrm{N}$ where $\mathrm{N}>1$. Small amounts of alkyl substitution, fused-ring structure, and cycloalkyl rings are present. The hexaphenyls resulting from the electron irradiation of pure $\mathrm{o-}, \mathrm{m}-$, and $\mathrm{p}$-terphenyls have been studied gas chromatographically in this laboratory [10]. Conventional chemical analyses such as carbon, hydrogen, oxygen, ash, metals, molecular weight, and unsaturation as well as physical tests such as melting point, viscosity, etc, have been run.

The variety of experiments described below are attempts to further understand the structure of the "high-boiler" products. The work has suggested other methods for characterizing this very complex mixture of products. 


\section{EXPERIMENTAL, RESULTS, AND DISCUSSION}

The majority of the experiments were performed on OMRE Core 2 "high boiler". This was a pot residue removed from terphenyl coolant which had circulated in the OMRE to an accumulated radiation exposure of $865 \mathrm{Mwd}$. The pot residue was obtained by flashing off the terphenyls and other "low boilers" present at $510^{\circ} \mathrm{F} / 20 \mathrm{~mm} \mathrm{Hg}$. Conventional analyses performed on this material, designated OMRE HB hereafter, gave the results shown in Table I.

\section{TABLE I}

AILALYSIS OF OMRE. HIGH BOILER

$$
\begin{aligned}
& \% \text { Carbon - } 94.5 \\
& \% \text { Hydrugen }-5.5 \\
& \% \text { Oxygen - } 0.1 \\
& \% \text { Nitrogen }-0.01
\end{aligned}
$$

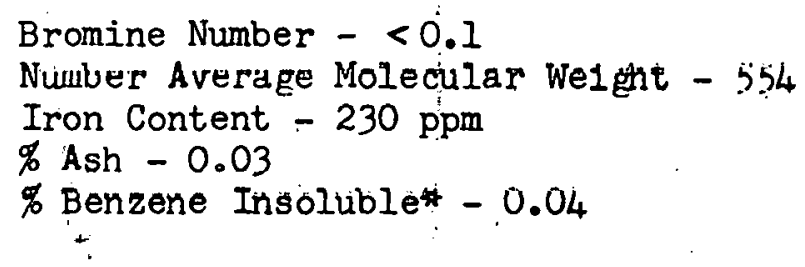

* $5 \%$ sample in benzene put through 0.45 micron Millipore filter, residue washed with benzene and weighed. Analyzed as follows: $\mathrm{C}=86.1 \% ; \mathrm{H}=3.9 \% ; \mathrm{O}=0.1 \%$ (probably contains ash). Electron spin resonance spectroscopy showed the presence of unpaired electrons resembling those found in asphaltic materials; $\mathrm{mp}>510^{\circ} \mathrm{C}$.

All infrared spectra included in this, report were taken on a Model 137 Perkin-Elmer Infracord.

\section{DISTILLATION OF OMRE HIGH BOILER}

Two distillations of OMRE HB have been performed.

\subsection{Small-Scale Fractionation}

Two hundred fifty grams of OMRE HB were fractionated through a onefoot Vigreux column. Data obtained on the cuts are shown in Table II.

Recalculating the original molecular weight from the molecular weights of the cuts gave a 536-gram value which indicated that little decomposition occurred during distillation. Considerable quaterphenyl- and hexaphenyl-like material was present in fractions $A$ and $B$ as shown by molecular weights, 306 and 458 grams, respectively. A crude gas chromatographic analysis of the fractions indicated the presence of 13 percent $\mathrm{m}$ - and $\mathrm{p}$-terphenyl, 10 percent quaterphenyls, and 77 percent higher materials. $\mathrm{C} / \mathrm{H}$ ratios increased with increasing molecular weight as would be expected for higher polyphenyls (see Table III). 


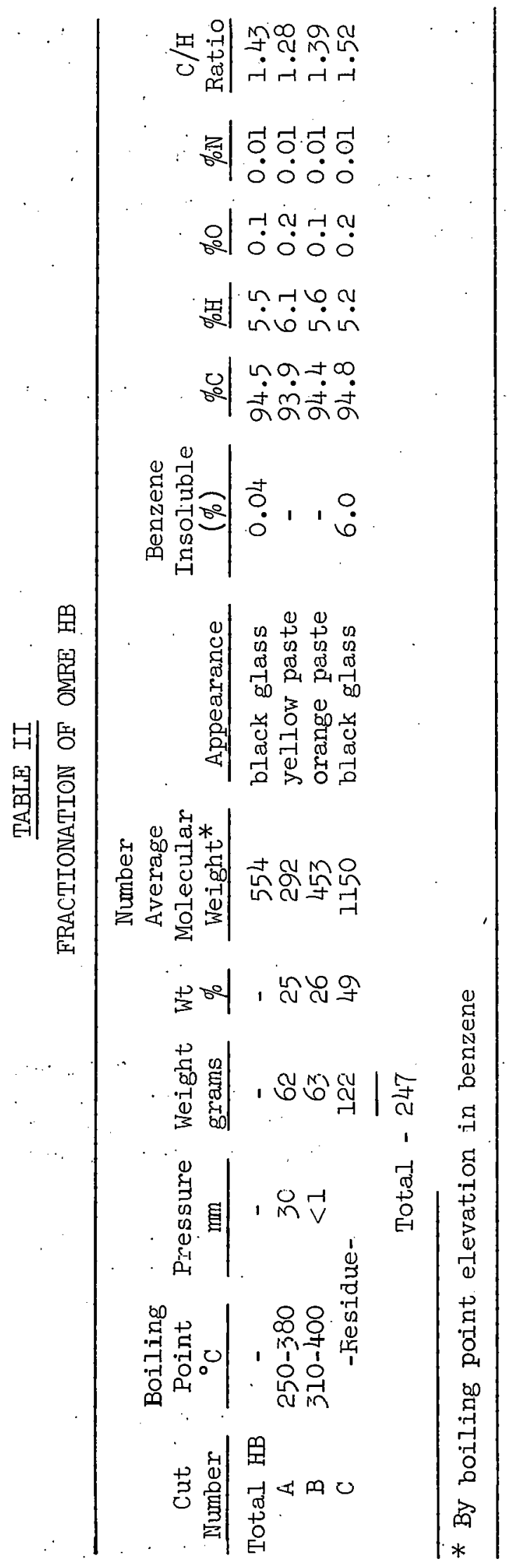

TABIE III

C/H RATIO FOR POLYPHENYLS

\begin{tabular}{lc}
\hline \multicolumn{1}{c}{ Polyphenyl } & C/H Ratio \\
Terphenyls & 1.28 \\
Quaterphenyls & 1.33 \\
Hexaphenyls & 1.38 \\
Infinite Polyphenyl & 1.50 \\
\hline
\end{tabular}

The solubility of residue $\mathrm{C}$ in benzene indicated that either the removal of lower-boiling fractions affected the solubility of the residue or a chemical change had taken place. The insoluble naterial analyzed 94.4 percent carbon, 4.3 percent hydrogen, 0.6 percent oxygen, and 0.003 percent nitrogen. The remainder was probably ash. The low hydrogen value, even considering the oxygen present, indicated possible dehydrogenation during heating, perhaps accompanied by ring closure or formation of fused-ring compounds. The latter are less soluble in solvents than the polyphenyls.

Infrared spectra of the various fractions from OMRE HB caused a noticeable difference between the spectra of the original material and the pot residue. A broad band at 11.2 microns became more prominent at 11.3 to 11.4 microns in the pot residue. $A$ band at 11.9 microns was diminished in the pot residue. These differences may indicate a decrease of single meta and para linkages in the high boiler (see Reference 10, infrared correlations section). The two benzene-insoluble materials were quite similar spectrally. A further enhancement of the peak shifts and diminutions as shown for cut $\mathrm{C}$ was noted. This may or may not be related to benzene insolubility.

Cuts A, B, and C were heated with picric acid in chloroform solution in an attempt to form insoluble picrates 
with any fused-ring compounds present. Complex formation was indicated by the deepened color of the solutions. However, only cut A gave a precipitate which proved to be mainly the picrate of triphenylene.

Using anthracene picrate in benzene as a model compound, various chromatographic columns were examined for their ability to retain the picrate without decomposition. Silica gel, alumina, and Fluorosil $\left(\mathrm{MgSiO}_{3}\right)$ destroyed the picrate. No adsorption of the picrate occurred on firebrick, anhydrous magnesium sulfate, or $13 \mathrm{x}$ mole sieve. Since a satisfactory column could not be found, chromatographic separations of the high-boiler picrates was not attempted.

\subsection{Larger-Scale Flash Distillation}

A second flash distillation on a larger scale gave the data shown in Table IV.

This distillation required a considerably longer. time than the first distillation. Apparently the reactionforming benzene-insoluble material is time dependent since the percentage in Table IV was double that of the first distillation (Table II). This indicates that a reaction was occurring during distillation to form the insoluble material. Speculations on what caused this increasing amount of benzene-insoluble material are included later in this report.

TABLE IV

DISTILLATION OF OMRE HB

\begin{tabular}{lc}
\hline Original Weight & $1000 \mathrm{~g}$ \\
Distilling to $380^{\circ} \mathrm{C} /<1 \mathrm{~mm}$ & $490 \mathrm{~g}$ \\
Distilled & $49 \%$
\end{tabular}

Benzene Insoluble Material in Pot Residue - 12\%

\section{SOLVENT FRACTIONATION OF OMRE HB}

Several solvent pair fractionations of OMRE HB were performed.

\subsection{Methanol/Benzene Syslem}

Fifty gramo of OMRE HB were dissolver in $500 \mathrm{ml}$ of henzene and methanol slowly added. Filtration did not prove satisfactory for removing insoluble material so centrifugation was used, followed by decantation of the supernatant liquid. Complete separation of the phases was not accomplished by this procedure but the results shown in Table $\mathrm{V}$ were obtained.

The glass flasks containing the solutions for molecular weight determinations of the above fractions were coated with a brown film after standing for a day. The amount of film deposited increased with molecular weight of the fraction. These deposits are discussed later in this report.

Benzene/methanol did not prove to be a very satisfactory solvent pair for fractionation of OMRE HB as the precipitates tended to be oily. However, a rough molecular weight distribution was obtained.

\subsection{N-Penthane/Benzene System}

2.21 Total OMRE HB. One hundred grams of OMRE HB were dissolved in $500 \mathrm{ml}$ of benzene and centrifuged to remove $43 \mathrm{mg}$ of insoluble material. 
‥ SOLVENT FRACTIONATION OF OMRE. HB WITH BENZENE/METHANOL

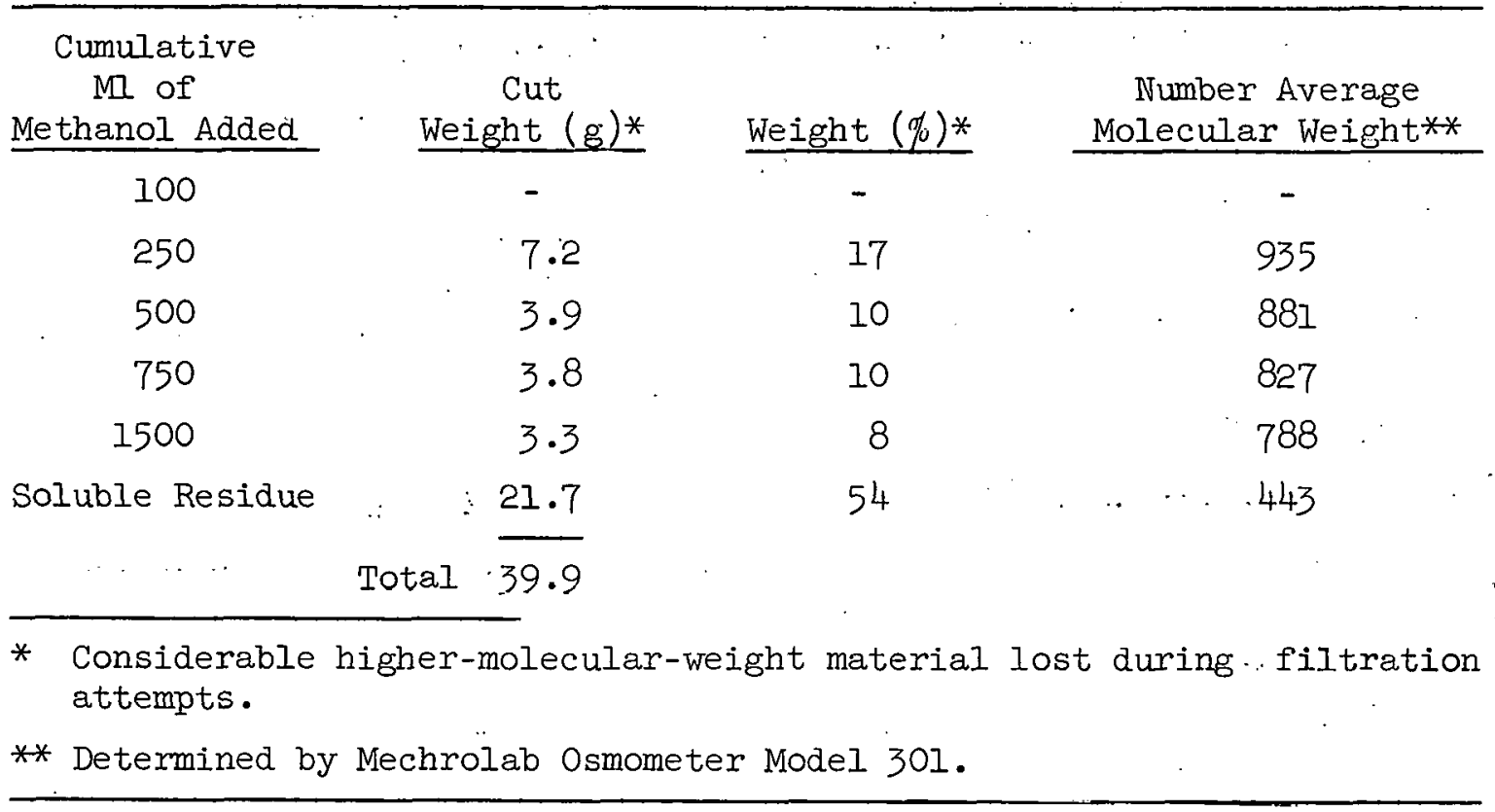

It was then fractionated by addition of $\mathrm{n}$-pentane as shown in Table VI. The precipitates. were recovered by filtration.

TABLE VI

SOLVENT FRACTIONATION OF OMRE HB WITH BENZENE/N-PENTANE

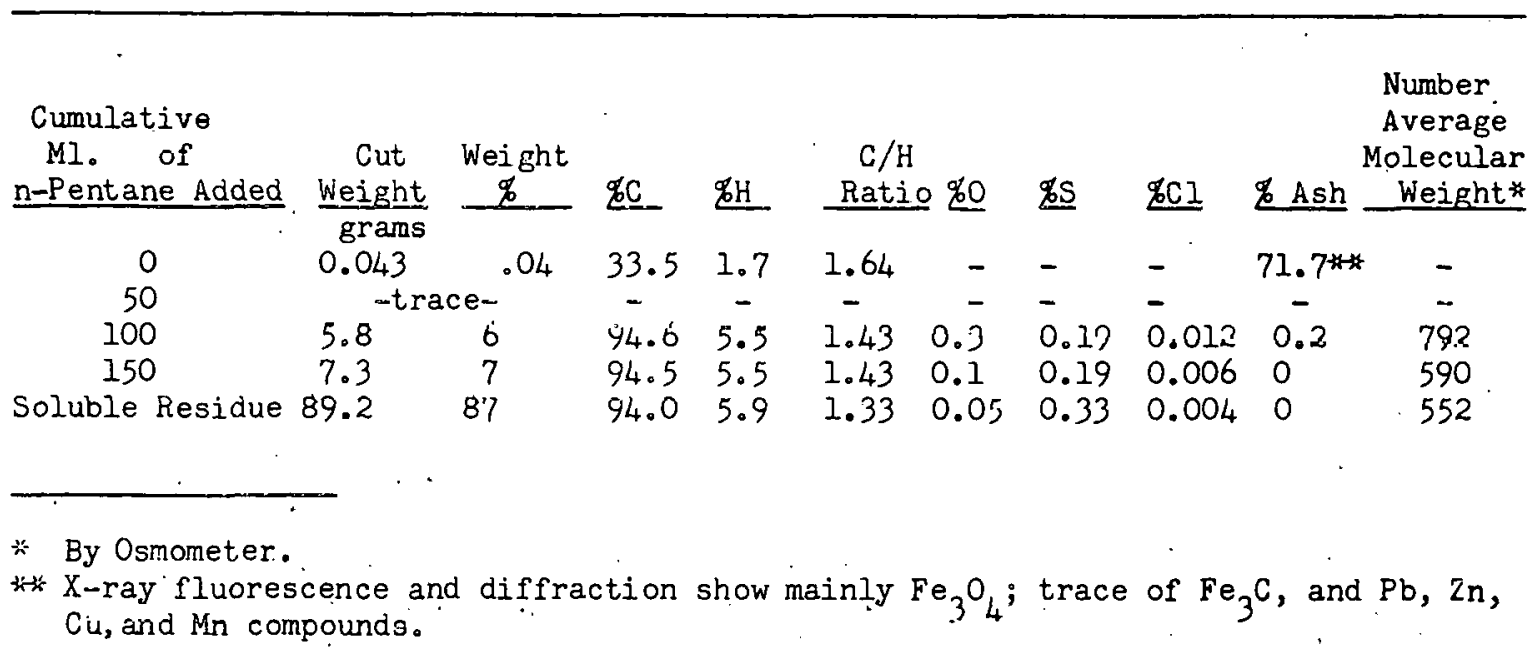

Infrared spectra of the fractions in Table VI showed very little differences. The narrow spread in the molecular weights among the fractions indicated this solvent system was not adequate for good distribution.

2.22 Pot Residue from Distilled OMRE HB. One hundred grams of the pot residue from the distilled OMRE HB described in Section II, 1.2 of this report 
were mixed with $500 \mathrm{ml}$ of benzene and $\mathrm{n}$-pentane added as shown in Table VII. Filtration was used to separate the insoluble material from the solution. At the start of this fractionation it was not realized that so much benzene-insoluble material was present; hence the unusual procedure was used.

TABLE VII

SOLVENT FRACTIONATION OF POT RESIDUE

FROM DISTILLED OMRE HB WITH BENZENE/N-PENTANE

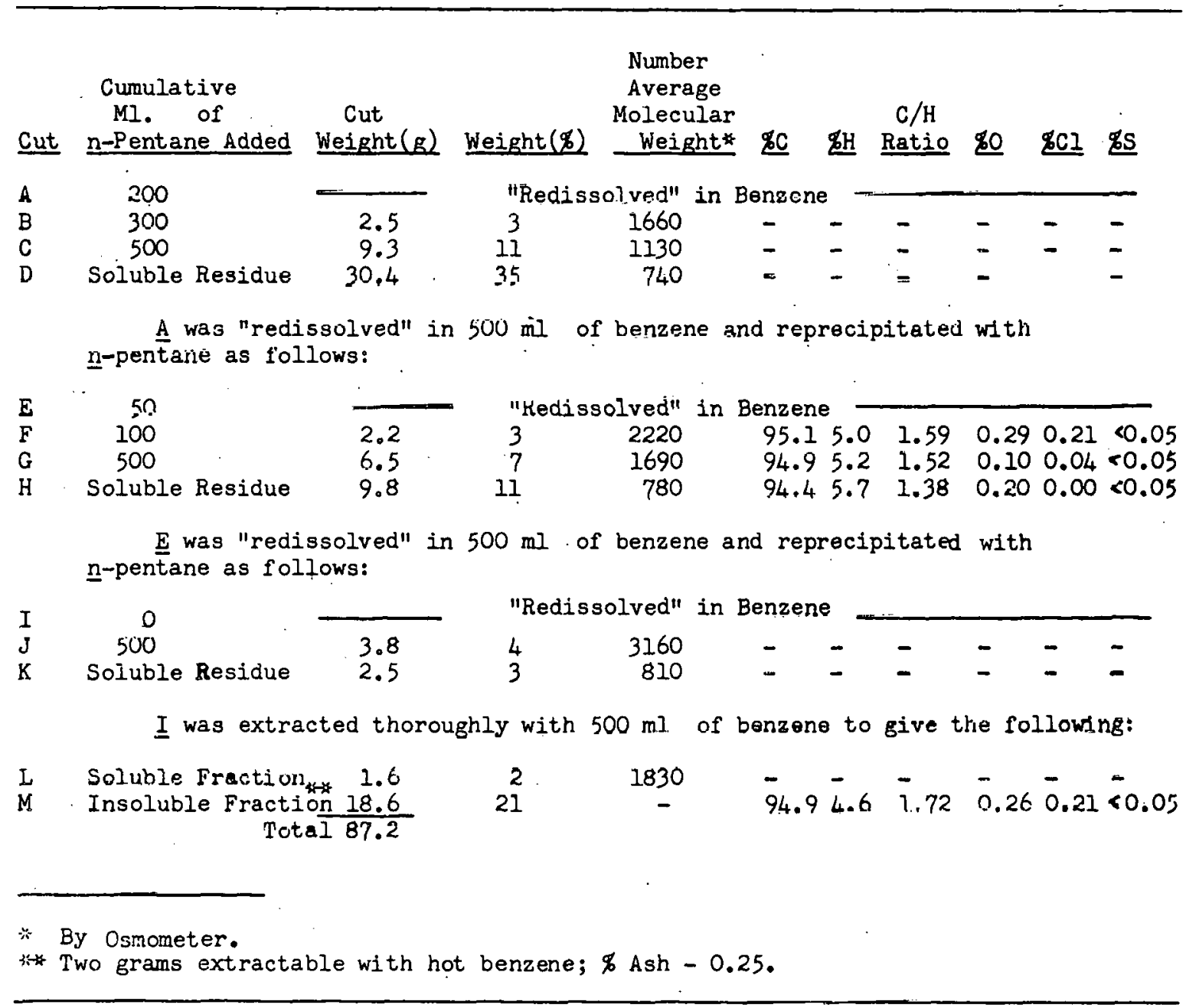

Fraction M, although benzene insoluble, was readily soluble (or dispcrsible) in a molten terphenyl mixture ( 10 ortho $/ 60$ meta $/ 30$ para). The infrared spectrum of fraction $M$ was identical to those of the benzene insoluble fractions shown in Figures la and 1b. The amount of chlorine present in fractions $F$ and $M$ was unusual. Fraction $\mathrm{M}$ was refluxed two hours with 20 percent aqueous $\mathrm{NaOH}$ and the inorganic chloride determined. Only one-tenth of the chlorine was hydrolyzable. Further treatment with alcoholic $\mathrm{KOH}$ failed to remove more chlorine. Therefore the chlorine must be bound tightly, perhaps as an aryl chloride. The fact that chlorine is present in the higher-molecular-weight, more insoluble fractions may have a bearing on film-forming tendencies of these materials. Possibly a bond between metal and organic may be formed by an organometallictype reaction. 


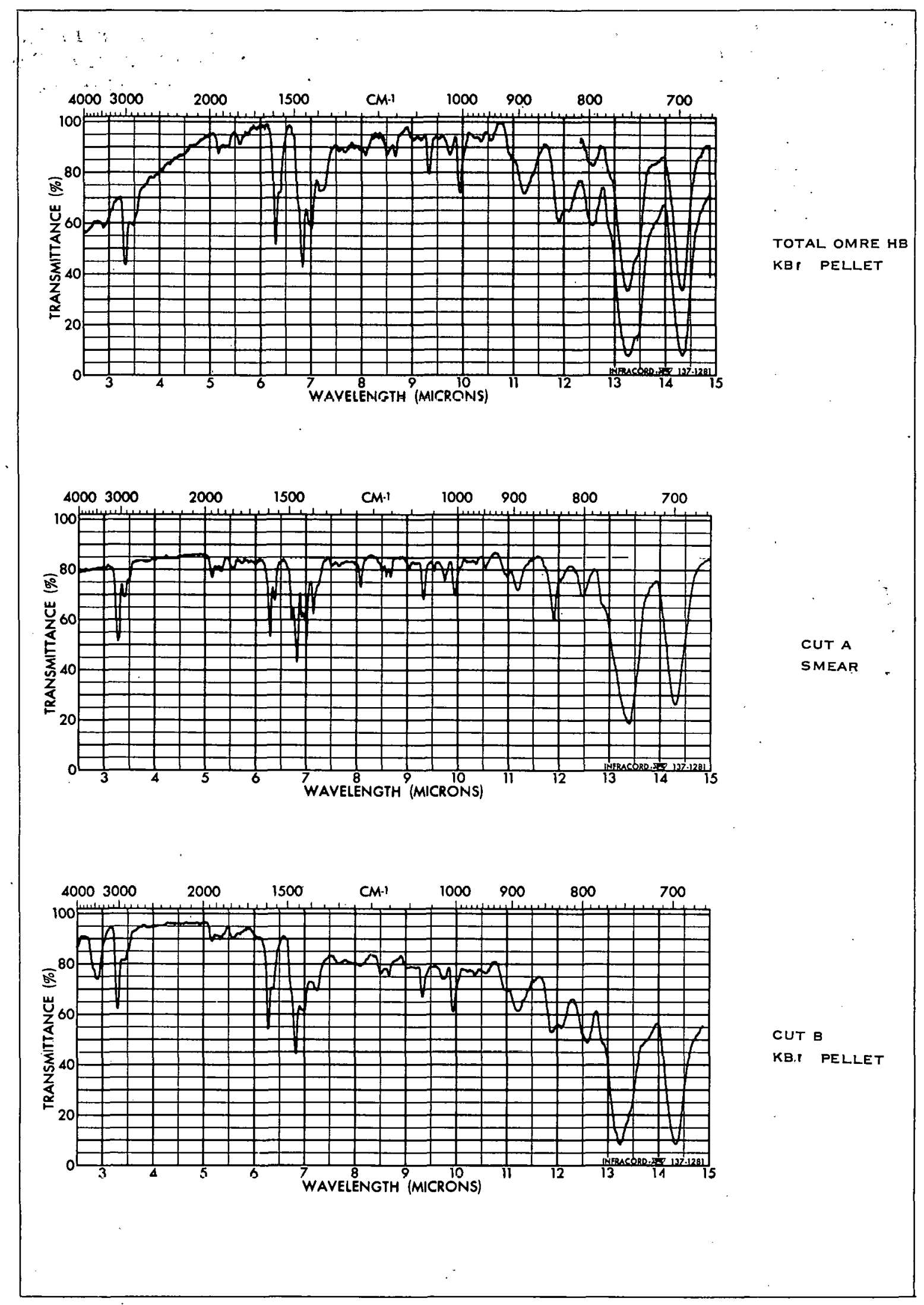

Fig. la Infrared spectra of fractions isolated from OMRE high boller. 


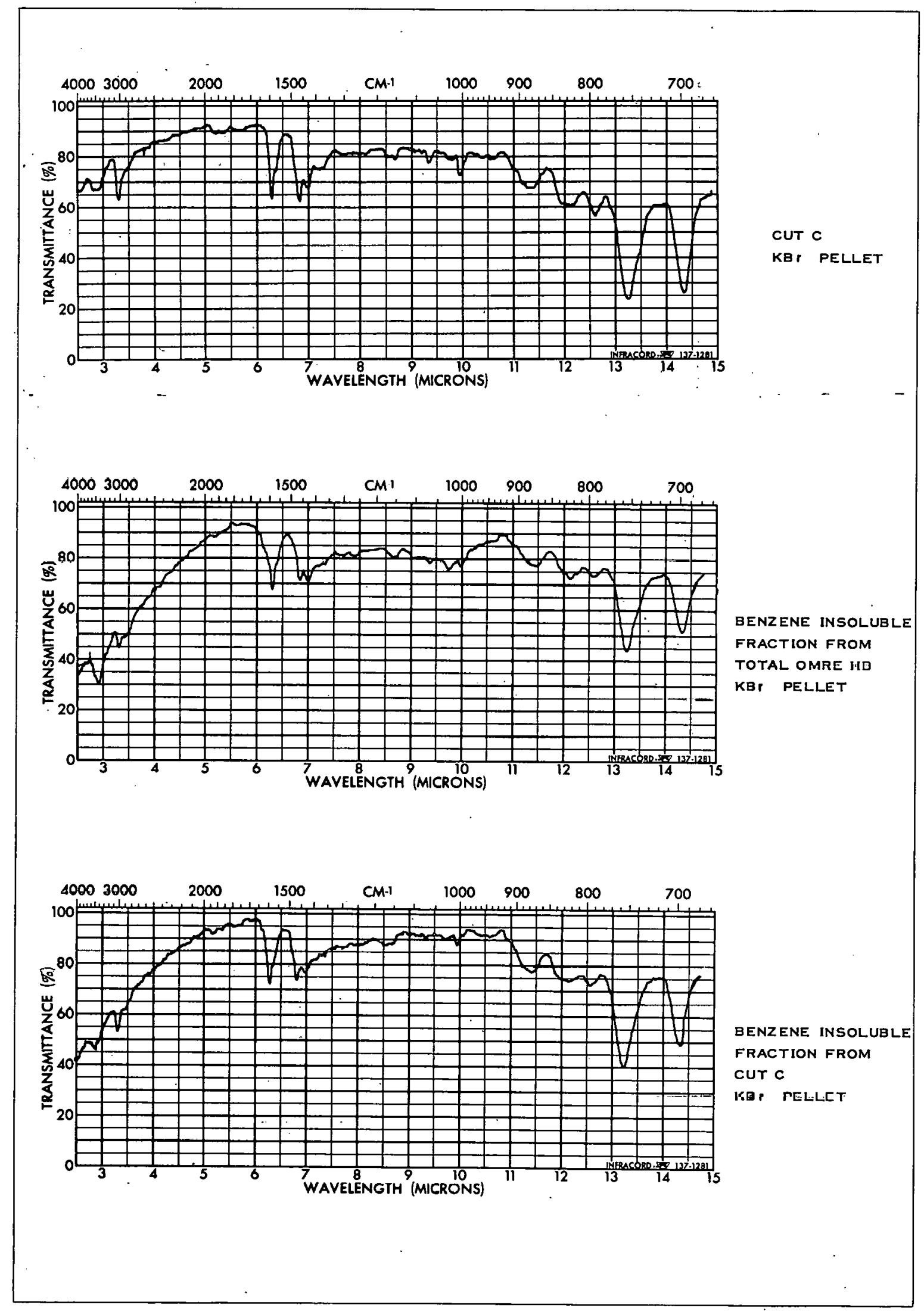

Fig. lb Infrared spectra of fractions isolated from OMRE high boiler. 
Benzene solutions of the fractions shown in Table. VII were allowed to stand in glass containers for four days. Only fractions F, J, and L deposited brown adherent films on the glass. These are all high-molecular-weight fractions and should be suspected as film formers in atomic reactors.

Although the method used in obtaining the various fractions in this series was unorthodox, the fact remains that quite high molecular weight species were present in a polyphenyl coolant which had been irradiated for a considerable time in an atomic reactor.

\subsection{Cyclohexane/Benzene System}

A large-scale precipitation was performed with this system to recover considerable benzene-insoluble material for further work. Four kilograms of OMRE HB were dissolved in six liters of benzene, diluted with six liters of cyclohexane, and centrifuged. The precipitate after drying weighed 906 grams. This material was extracted exhaustively with hot benzene, in a Soxhlet, until no further colored material extracted. The remaining insoluble material weighed 40 grams which represented one percent of the original OMRE HB. It should be noted that the method of performing the original precipitation affects the amount of benzene-insoluble material obtained. For example, a simple solution of the material in benzene followed by filtering gave only 0.04 percent benzene insolubles.

The benzene-insoluble material isolated in this case gave the analysis shown in Table VIII.

TABLE VIII

ANALYSIS OF BENZENE-INSOLUBLE OMRE HB

FROM CYCLOHEXANE/BENZENE SOLVENT FRACTIONATION

$\begin{array}{rll}\% \mathrm{C}-94.1 & \% \mathrm{Cl}-0.07 \text { Infrared Spectrum shown in Figure } 4 . \\ \% \mathrm{H}-5.0 & \% \mathrm{~S}-<0.1 \\ \mathrm{C} / \mathrm{H} \text { Ratio }-1.57 & \% \mathrm{~N}-0.04 \\ \% \mathrm{O}-0.41 & \% \mathrm{Ash}-0.77\end{array}$

This material was examined in film-forming tests and found to give extremely heavy films. It was studied further by chemical means in an effort to understand its composition.

3. CHARACTERIZATION OF OMRE HB BY WEIGHT AVERAGE MOLECULAR WEIGHT

Changes in high-molecular-weight fractions of OMRE HB are not easily detected by the usual number average molecular weight $\overrightarrow{\mathrm{M}} n$. This measure is not too sensitive to higher-weight molecules and it is these higher-weight 
molecules which may be associated with fouling. Weight average molecular weight $\overline{\mathrm{M}} w$ is sensitive to changes in the high-molecular-weight portion of the distribution. : The use of light scattering or centrifugation methods for $\overline{\mathrm{M}} w$ is prevented by the dark color of the high boiler.

A high-boiler profile was prepared by removing varying amounts of sublimate from the high boiler and determining the $\overline{\mathrm{M}}$ n for each residue on a Mechrolab osmometer. The osmometer had been calibrated with biphenyl, $\mathrm{m}$-terphenyl, and benzil. Readings were taken two minutes after the drop was placed on the thermistor. A benzene solution of OMRE HB was used and its solubility checked by evaporating aliquots; and the weight residue checked with the calculated weight. Agreement was good in all cases.

Sublimations were performed as follows: (a) one- to two-gram samples were run at $5 \times 10^{-2}$ or $2 \times 10^{-5} \mathrm{~mm} \mathrm{Hg}$; (b) the temperature was raised slowly for two hours until the desired amount of sublimate was obtained; and (c) the fractions (sublimate and residue) : were weighed. The resulting weight fractions of the residues were plotted against their respective number average molecular weight. Weight average molecular weight $\overline{\mathrm{M}} \mathrm{w}$ was found to be superior to $\overline{\mathrm{M}} \mathrm{n}$ as a means of indicating the effect of radiation on high boiler.

Sublimation of the lower fractions magnified the changes in $\overline{\mathrm{M}} \mathrm{n}$ which occur in the residue. These changes in the high ends were accentuated by radiation of the high boiler. Treatment of the high boiler with carbon black in benzene solution (1:1 HB/carbon black) showed a reduction in heavy ends by adsorption. These data are shown in Figure 2. These treatments changed the $\overline{\mathrm{M}}$ n of the total sample little: (a) HB, 541; (b) irradiated HB, 573; (c) HB treated with carbon black, 504 .

Small changes in $\overline{\mathrm{M}} \mathrm{n}$ may be accompanied by greater changes in $\overline{\mathrm{M}} \mathrm{w}$; thus $\overline{\mathrm{M}} \mathrm{w}$ should provide a more accurate picture of radiation damage. Using the sublimation procedure previously described, the weight fraction was plotted against $\overline{\mathrm{M}}$ n on $\log -\log$ coordinates (Figure 3 ). Straight lines of different slopes were obtained for the three conditions. The larger the magnitude of the negative slope, the lower was the high-molecular-weight content of the sample.

Figure 3 was used in the calculation of approximate $\overline{\mathrm{M}} \mathrm{w}$. If a given sample is divided into 10 equal cuts by sublimation, $\overline{\mathrm{M}} \mathrm{w}$ can be determined from the relationship:

$$
\overline{\mathrm{M}} \mathrm{w}=\sum_{\mathrm{n}=1}^{\mathrm{n}=9} 0.10 \mathrm{M}_{\mathrm{SN}}+0.1 \mathrm{M}_{0.1}
$$

where MSN is the number average molecular weight of the $\mathrm{N}^{\text {th }}$ sublimate (1 through 9). Each MSN term is included in the summation. The last term, $\mathrm{M}_{0.1}$, in Equation (1) is the number aveage molecular weight of the final $1 / 10$ residue which is left after the ninth sublimation. This. term is constant for each system. The molecular weights $\overline{\mathrm{M}} \mathrm{n}$ of each of the nine fractions can-be calculated using-Figure 3. For .example, the molecular weight of the first sublimate fraction $\mathrm{M}_{\mathrm{S} 1}$ would be: 


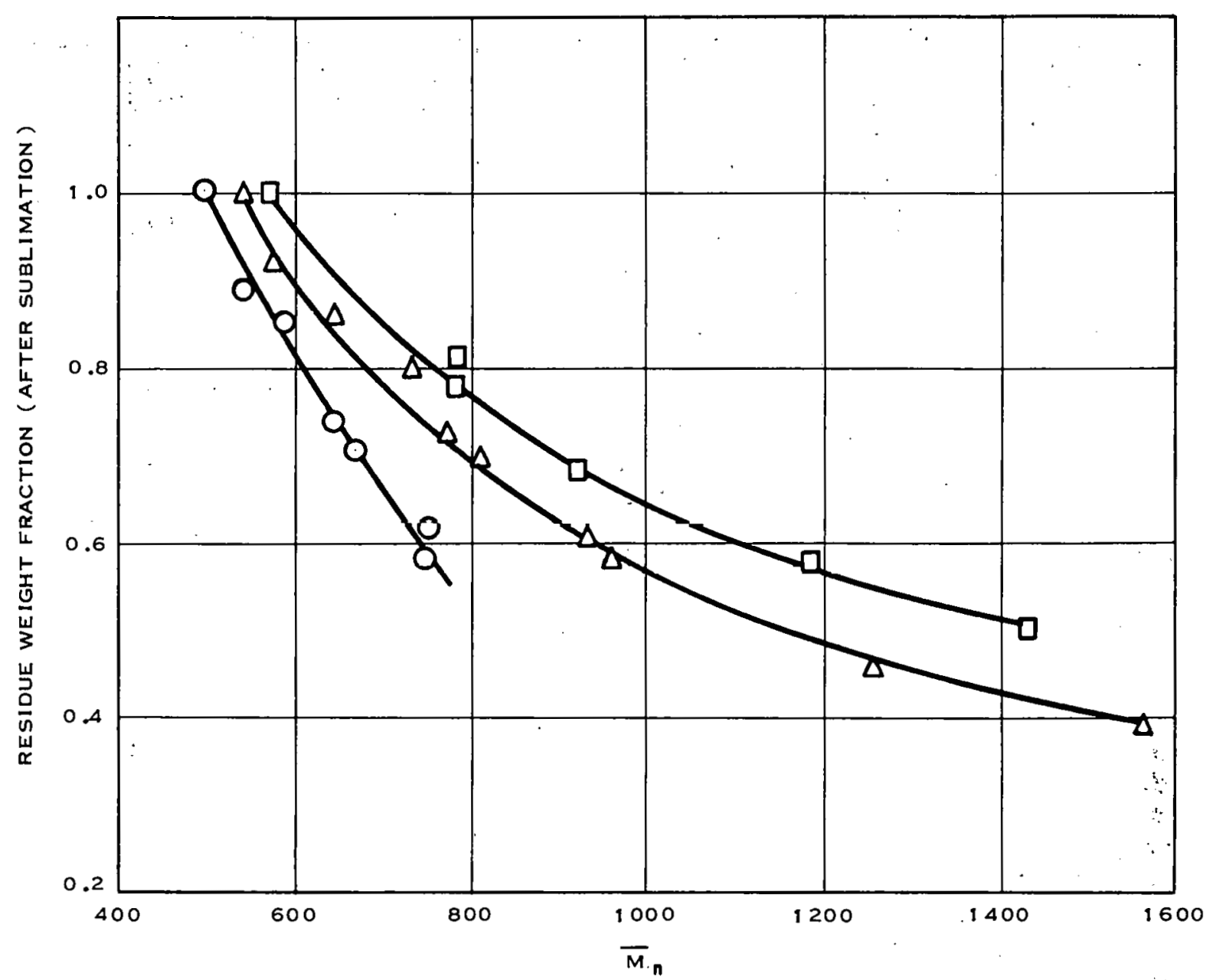

$\triangle$ OMRE HIGH BOILER

口 IRRADIATED OMRE HIGH BOILER

O OMRE HIGH BOILER TREATED WITH WYEX CARBON BLACK

Fig. 2 Molecular weight profile of high boiler.

$$
\mathrm{M}_{\mathrm{S} 1}=\frac{0.1}{\frac{1.0}{\mathrm{M}_{1.0}}-\frac{0.9}{\mathrm{M}_{0.9}}}
$$

where $\mathrm{M}_{1.0}$ is the average molecular weight for the total sample and $\mathrm{M}_{0.9} 9$ is the number average molecular weight for the residue after 10 percent had been sublimed. Thus, the molecular weight of the second sublimate fraction would be:

$$
\mathrm{M}_{\mathrm{S} 2}=\frac{0.1}{\frac{0.9}{\mathrm{M}_{0.9}}-\frac{0.8}{\mathrm{M}_{0.8}}}
$$




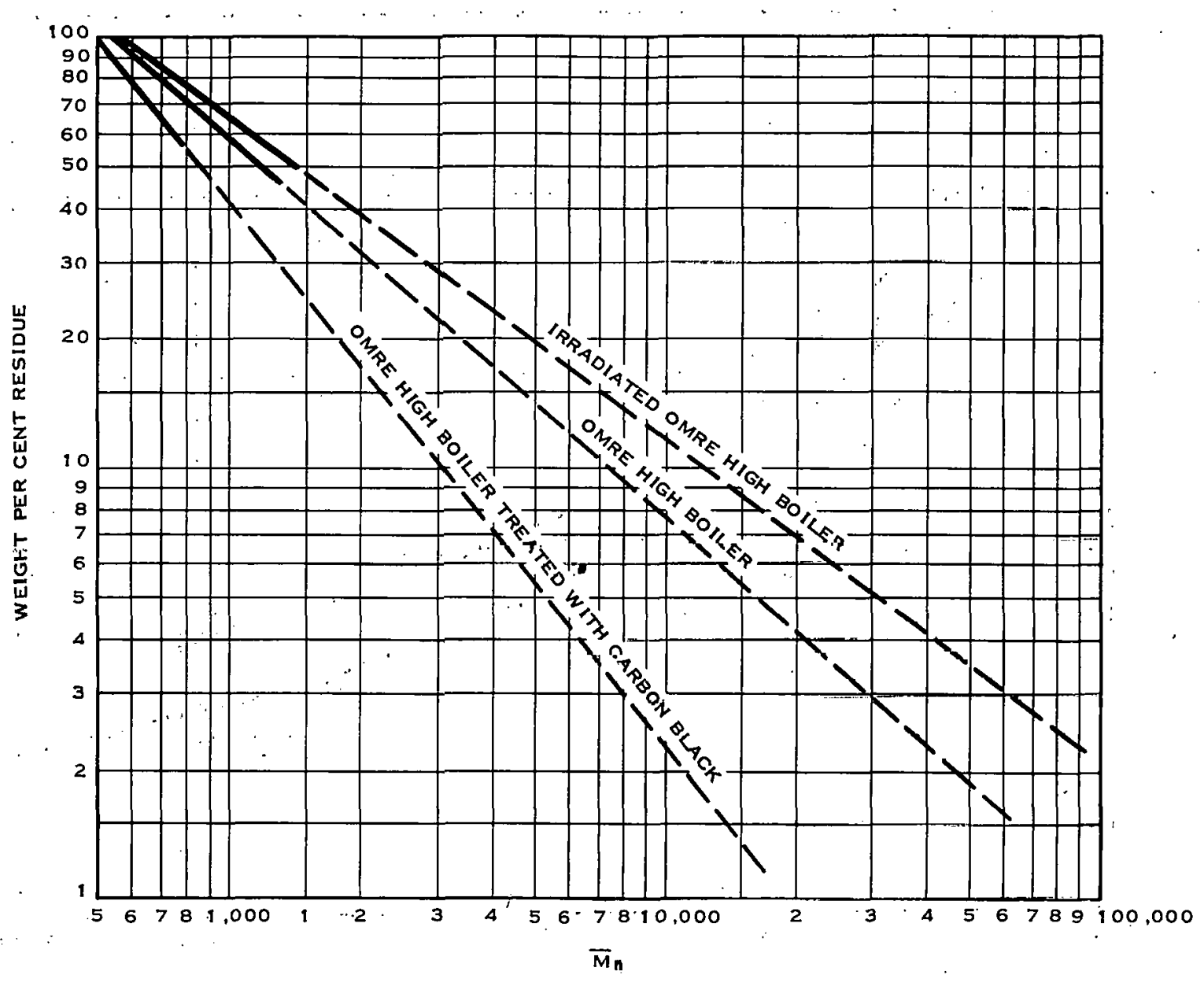

SOLID LINE - EXPERIMENTAL DATA

DASH LINE EXTRAPOLATED

Fig. 3 Log residue vs $\log \overline{\mathrm{M}}$.

where $\mathrm{M}_{0.8}$ is the number average molecular weight of the residue after 20 percent had been sublimed.

The general equation for the molecular weight of the residue (Figure 3 ) is:

$$
\dot{\mathrm{M}} \mathrm{w}=\mathrm{M}_{1.0} \mathrm{~W}^{1 / \mathrm{b}}
$$

where again $\mathrm{M}_{1.0}$. is the number average molecular weight of the total sample. $W$ is the weight fraction of the residue, $b$ is the slope of the curve, and MW is the number average molecular weight of the Wth weight fraction in the residue (not to be confused with $\overline{\mathrm{M}} \mathrm{w}$, weight average molecular weight).

Using Equation (1) through (4), an equation for the weight average molecular weight was developed: 


$$
: \bar{M}_{w}=\left(\frac{1}{10}\right)^{2} M_{1.0} \sum_{n=1}^{n=10} \frac{1}{[1-0.1(n-1)] \frac{b-1}{b}-[1.0 .1 n] \frac{b-1}{b}}
$$

Equation (5) requires only the molecular weight of the total sample, $\mathrm{M}_{1.0}$, and $\mathrm{b}$ the slope from Figure 3 . The calculation is valid if one assumes Equation (4) holds down to a residue of 10 percent.

Table IX shows the weight average molecular weights which were obtained

\section{TABLE IX}

HIGH-BOILER MOLECULAR WEIGHTS

\begin{tabular}{lcccc}
\hline \multicolumn{1}{c}{ Sample } & $\overline{\mathrm{M}}_{\mathrm{n}}$ & $\mathrm{v}$ & & $\overline{\mathrm{M}}_{\mathrm{W}}$ \\
\hline OMRE high boiler & & 541 & -0.92 & 1296 \\
Irradiated high boiler & 573 & -0.74 & 2118. \\
High boiler treated with carbon black & 504 & -1.22 & 852 \\
\hline
\end{tabular}

These results show the weight average molecular weights varied considerably when high boiler was irradiated or adsorbed on carbon black. The high values of $\overline{\mathrm{M}} \mathrm{w}$ confirm the curves in Figure 2 that show greater increases in the high ends of high boiler during radiation.

$\overline{\mathrm{M}}$ w's were calculated using a Royal-McBee LGP-30 digital computer. A sample may be divided arbitrarily into any given set of fractions such as 10 , 20, and 50. Only a few experimental points would be needed to establish the slope of the curve. This method may be used to evaluate the molecular weight changes in high boiler.

4. CHARACTERIZATION OF BENZENEINSOLUBLE MATERIAL PRESENT IN OMRE HB

The benżene-insoluble material (BIM) isolated by cyclohexane/benzene solvent fractionation (see Section II, 2.3) has been treated by a variety of chemical means in an effort to establish its structure.

\subsection{Hydrogenation}

Three hydrogenations were performed on BIM using a nickel-alumina catalyst (Girdler G-49) in a high-pressure rocking autoclave.

Sample Weight (grams)

Catalyst Weight (grams)

$\frac{\mathrm{A}}{3}+\frac{\mathrm{B}}{3}$


Continued:

Solvent Used.

Solvent Volume (ml)

Pressure (psig)

Temperature $\left({ }^{\circ} \mathrm{C}\right)$

Reaction Time (hours)

\begin{abstract}
$\frac{\mathrm{A}}{\text { decalin }}$
\end{abstract}
15

1000

177

15

\section{B \\ decalin}

10

2660

235

16
C

cyclohexane

70

3060

235

70

Run A

The product from run A was slurried in benzene, filtered, washed with more benzene, and the solvents removed from both fractions, finally drying in vacuo at $100^{\circ} \mathrm{C}$.

The benzene-insoluble material weighed 4.1 grams and analyzed 32.1 percent carbon, 2.1 percent hydrogen, 67.3 percent ash, and $\mathrm{C} / \mathrm{H}$ ratio was 1.27. It was Soxhlet extracted with boiling tetralin to remove further organic matter. The tetralin-insoluble material (catalyst) weighed 2.7 grams and analyzed 10.9 percent carbon, 1.3 percent hydrogen, and 88 percent ash (by difference). The tetralin-soluble material weighed 1.4 grams analyzing 83.1 percent carbon, 4.5 percent hydrogen, 3.0 percent oxygen, and 9.8 percent ash. It was a black powder similar to the starting BIM according to its infrared spectrum except slightly more aliphatic hydrogen appeared to be present (see Figure 4). No melting occurred up to $510^{\circ} \mathrm{C}$.

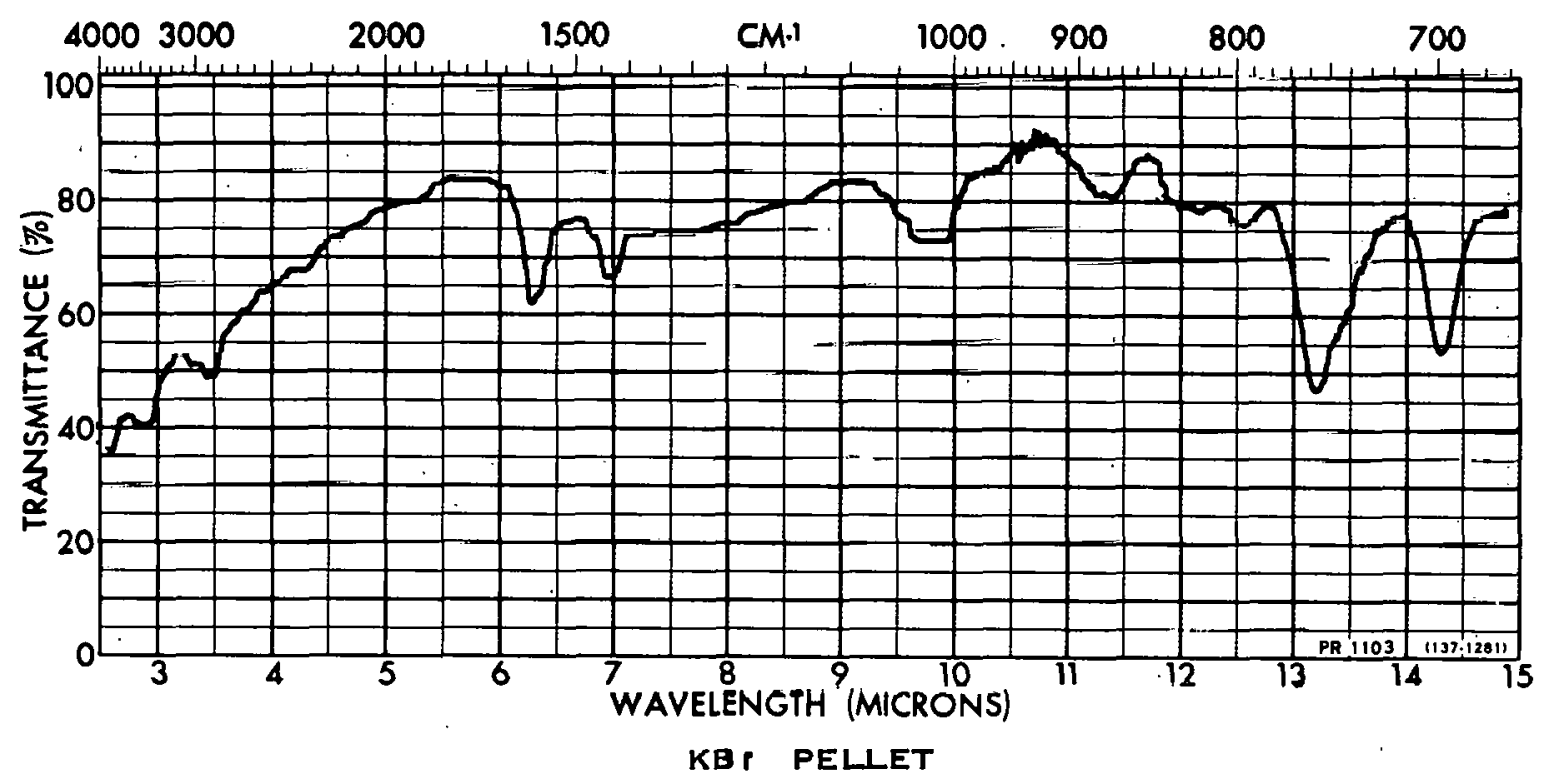

Fig. 4 Infrared spectrum of benzene-insoluble and boiling-tetralln-soluble hydrogenated BIM.

The oxygen present in the sample was not in carbonyl groups.

The benzene-soluble fraction was solvent fractionated with a benzene/npentane mixture. Table $\mathrm{X}$ shows the fractions isolated and analytical data on them. 
TABIEE $X$

BENZENE-SOLUBLE HYLROGENATED BIM*

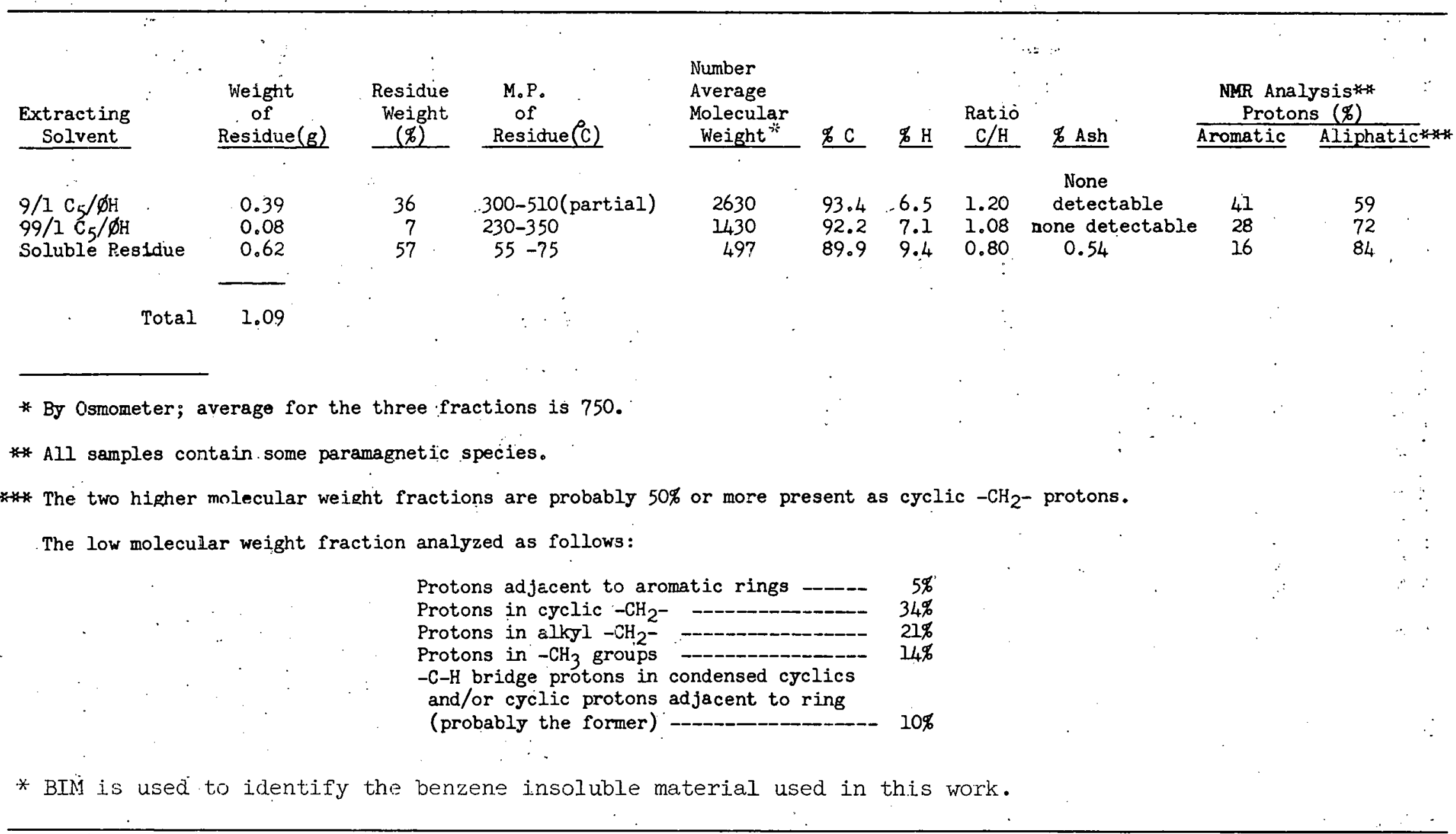


Apparently some low-molecular-weight product was lost during the workup procedure as only 5.2 grams of the original six grams of catalyst and sample were recovered.

$\underline{\text { Runs B and C }}$

The two solids (isolated as benzene-soluble and insoluble fractions as in run A) analyzed as shown in Table XI.

TABLE XI

PRODUCTS FROM HYDROGEITATED BIM

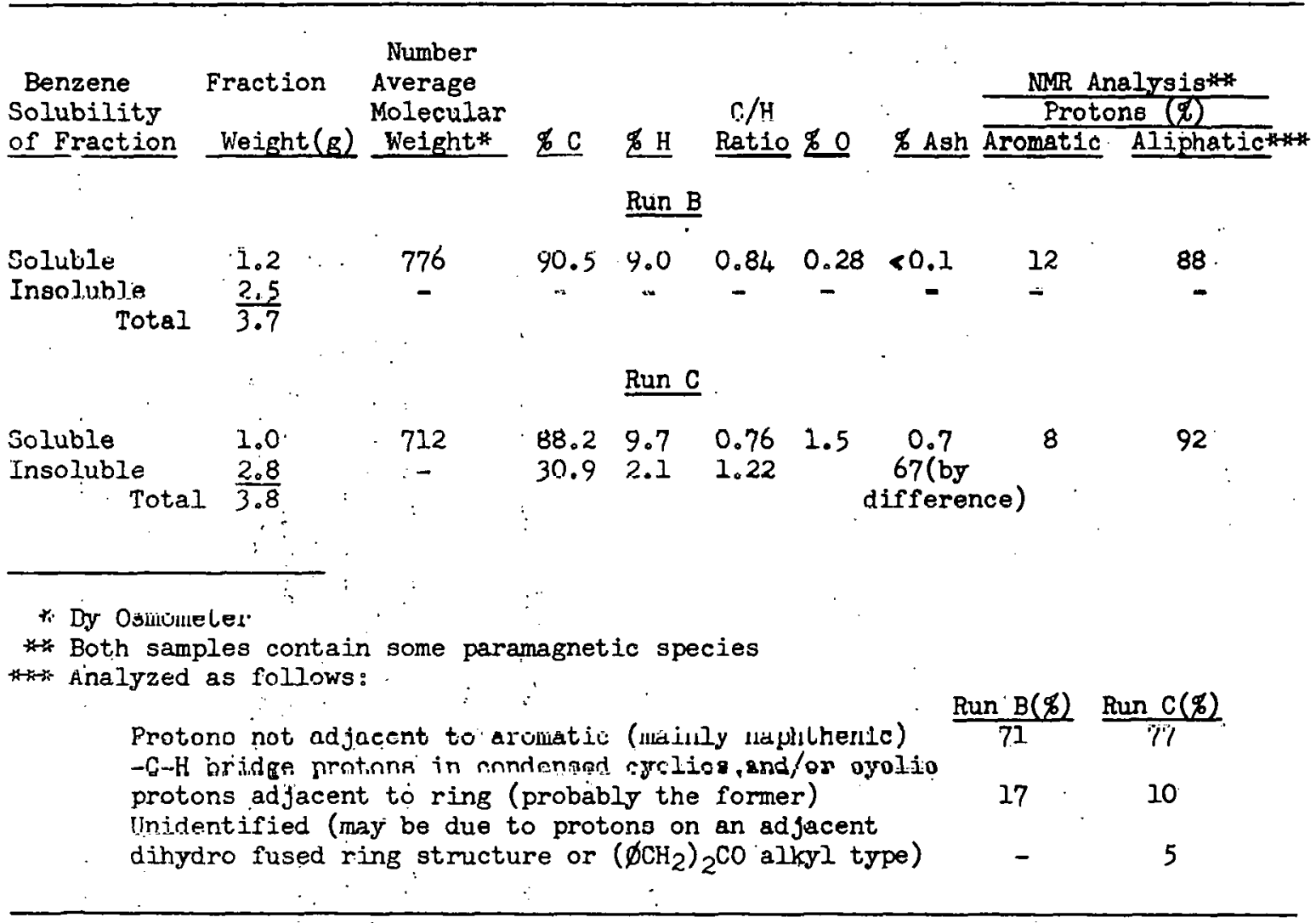

Recovery of material was better in runs $\mathrm{B}$ and $\mathrm{C}$ than in run $\mathrm{A}$ but there still appears to be some loss of volatile constituents.

Hydrogenation was definitely promoted by more severe snnditinns hut complete hydrogenation was never obtained. Considerable polyphenyl and fusedring structures were present in BIM as indicated by NMR analyses on hydrogenated material. There also appeared to he some straight-chain types prcscnt (- $\mathrm{CH}_{3}$ present after hydrogenation). The molecular. weight was quite high considering that only 30 to 50 percent of the material was benzene soluble even when fairly heavily hydrogenated.

Infrared spectra of the various hydrogenated fractions are shown in Figures $5 \mathrm{a}$ and $5 \mathrm{~b}$. 


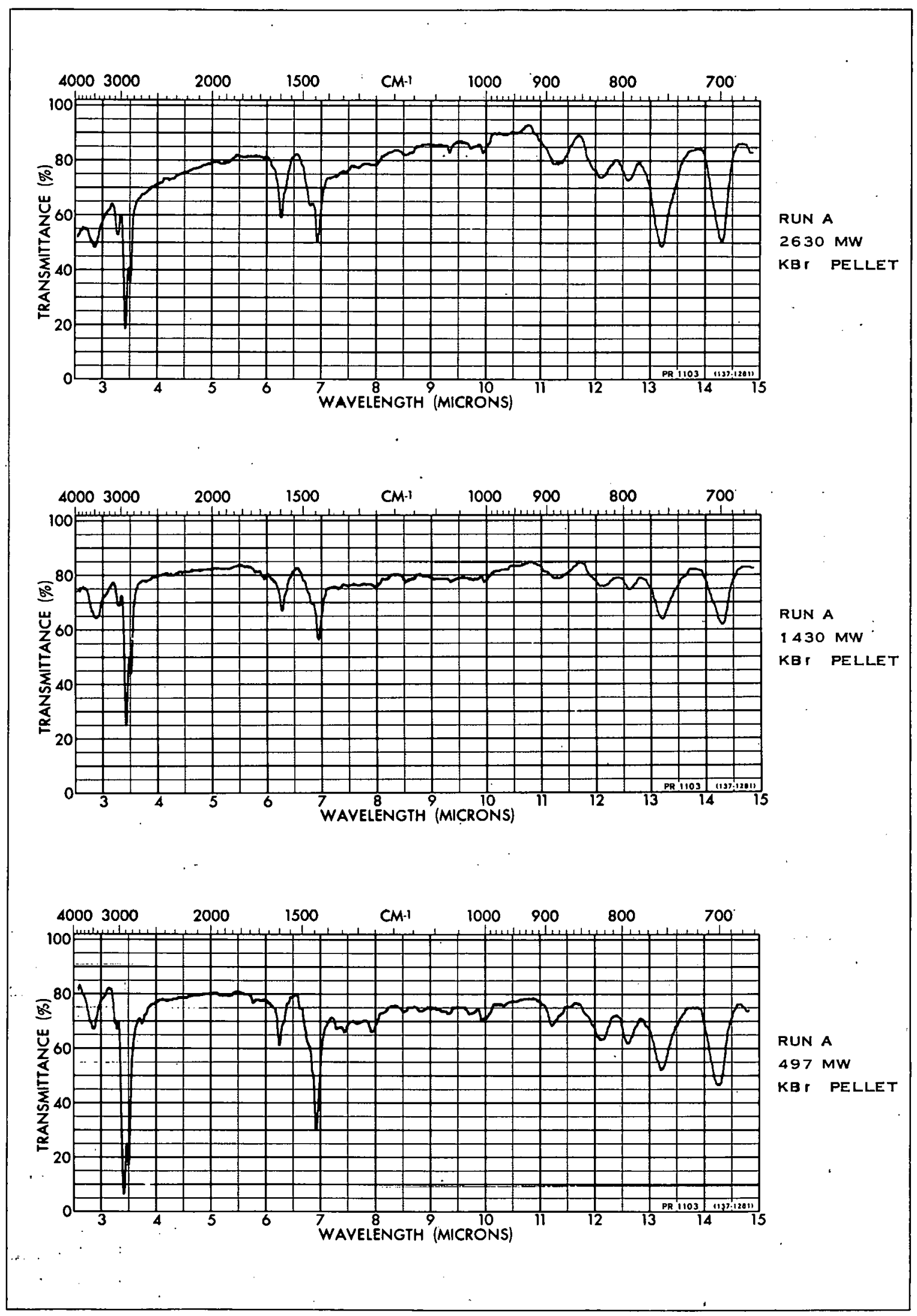

Fig. 5a Infrared spectra of benzene-soluble hydrogenated BIM fractions. 


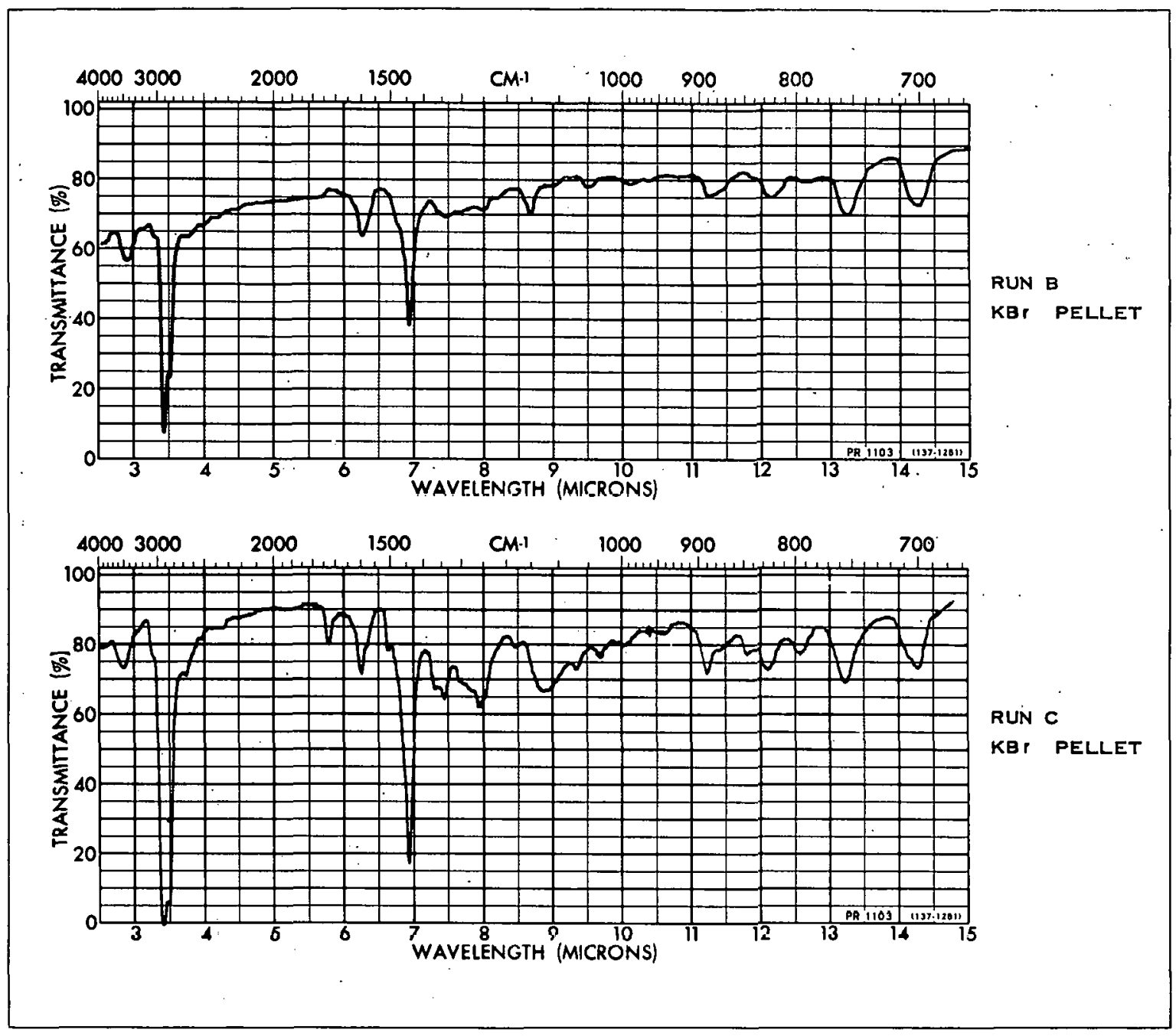

Fig. 5b linfrared spectrià of bénżene-soluble hydrogenated BIM fractions.

Infrared results confirmed the NMR trends. A small amount of carbonyl was present in the run $\mathrm{C}$ product. This must have been introduced during workup of the material. The "unidentified" aliphatic protons noted by NMR on this product can be assigned to hydrogens adjacent to carbonyl of the type shown in Table XI. Polyphenyl structure was still evident on the most highly hydrogenated product.

\subsection{Oxidation}

One gram of dry BIM was treated with 0.5 percent ozone in air for $30 \mathrm{~min}$ in an attempt to degrade the material. A total of $35 \mathrm{mg}$ of ozone was passed over the sample. BIM reacted with $17 \mathrm{mg}$ of ozone to produce a light brown powder. Analysis showed 92.2 percent carbon, 4.9 percent hydrogen, and 2.2 percent oxygen. Comparison with the analys is of BIM shown in Table XII indicates the oxidation reaction occurred at the expense of carbon. The infrared spectrum of the product showed only a slight introduction of carbonyl (Figure 6). No further work wa's performed along these lines. $\mathrm{KMnO}_{4} /$ pyridine oxidation on BIM will be found in Section II, 5.2. 
TABLE XII

TREATMENT OF BIM WITH $\mathrm{H}_{2} \mathrm{SO}_{4}, \mathrm{HNO}_{3}$, AND $\mathrm{Br}_{2}$

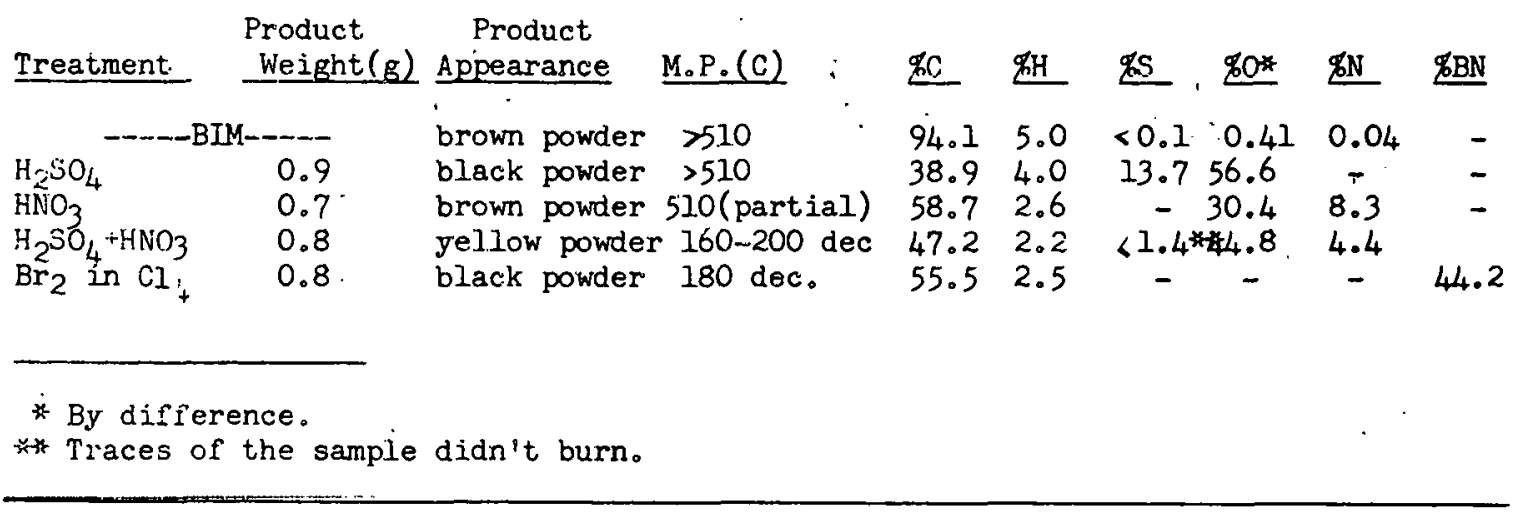

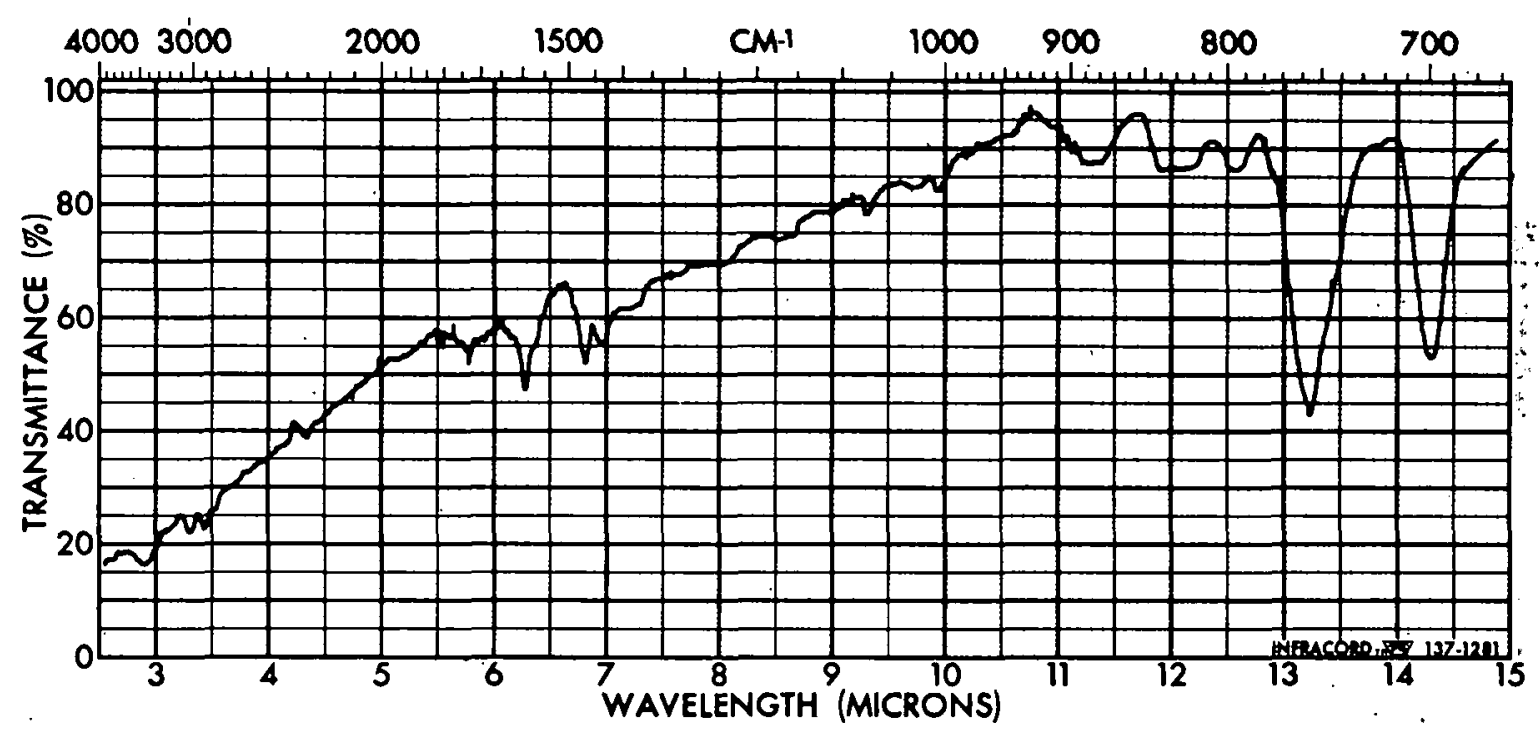

KB I PELLET

Fig. 6 Infrared spectrum of ozonized BIM.

\subsection{Reactions with $\mathrm{H}_{2} \mathrm{SO}_{4}, \mathrm{HNO}_{3}$, and $\mathrm{Br}_{2}$}

Five-tenths-gram samples of BIM were heated at $120^{\circ} \mathrm{C}$ for 3 hours with (a) $25 \mathrm{ml}$ of $\mathrm{H}_{2} \mathrm{SO}_{4}$, (b) $25 \mathrm{ml}$ of $\mathrm{HNO}_{3}$, and (c) $15 \mathrm{ml}$ of $\mathrm{H}_{2} \mathrm{SO}_{4}+15 \mathrm{ml}$ of $\mathrm{HNO}_{3}$. A fourth sample was treated at room temperature with $1 \mathrm{ml}$ of $\mathrm{Br}_{2}$ in $25 \mathrm{ml}$ of $\mathrm{CCl}_{4}$. The acid-treated samples were diluted with $\mathrm{H}_{2} \mathrm{O}$, washed well, and analyzed as shown in Table XII. Excess bromine and $\mathrm{CCl}_{4}$ were removed by evaporation, finally in vacuo at room temperature and then at $80^{\circ} \mathrm{C}$ with no loss in weight being noted on going to the higher temperature.

Infrared spectra of the four products are shown in Figures $7 \mathrm{a}$ and $7 \mathrm{~b}$. See Figures $1 \mathrm{a}$ and $1 \mathrm{~b}$ for total OMRE HB. 


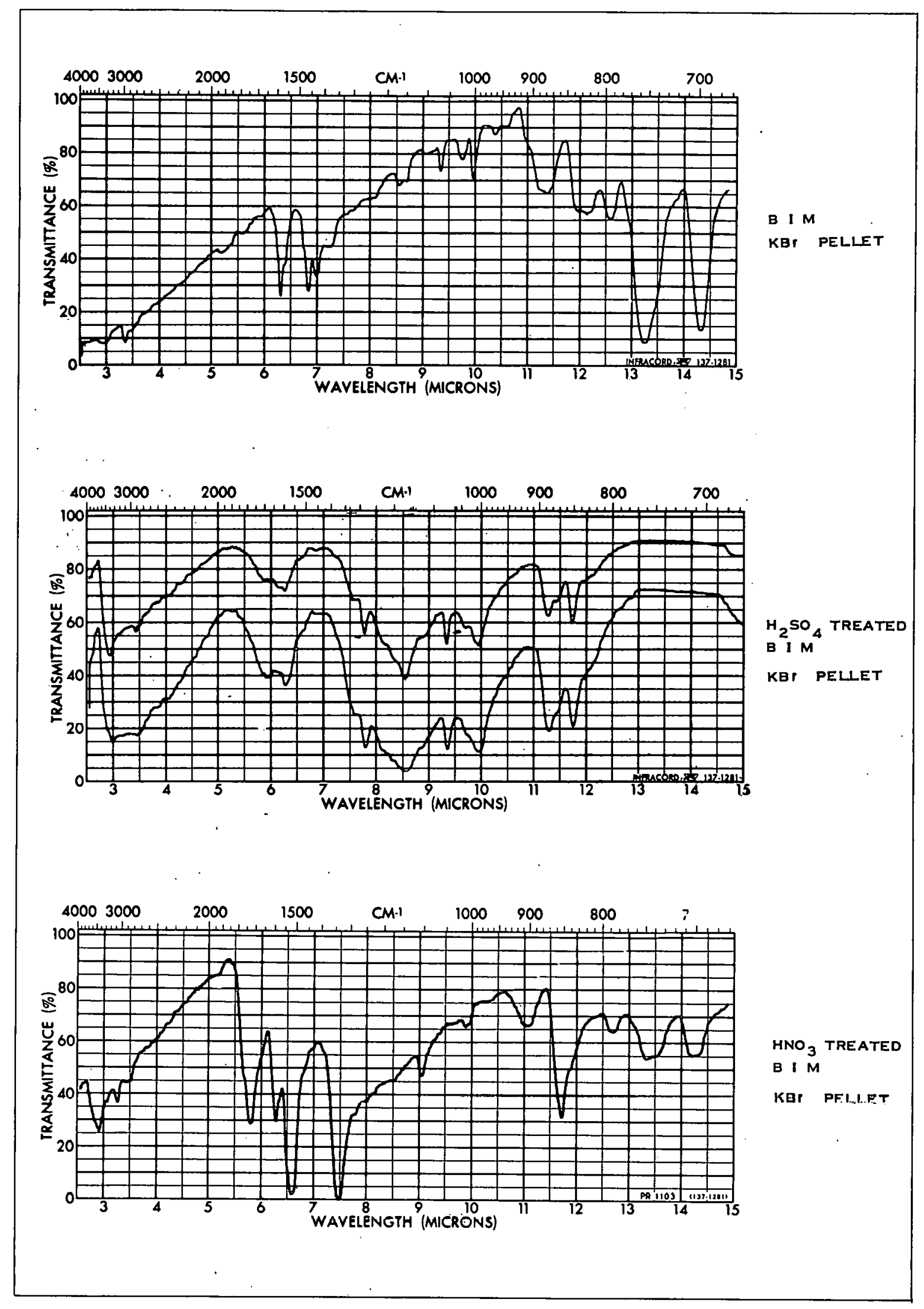

Fig. 7a Infrared spectra of $\mathrm{H}_{2} \mathrm{SO}_{4}, \mathrm{HNO}_{3}, \mathrm{H}_{2} \mathrm{SO}_{4} / \mathrm{HNO}_{3}$ or $\mathrm{Br}_{2}$-treated BIM. 


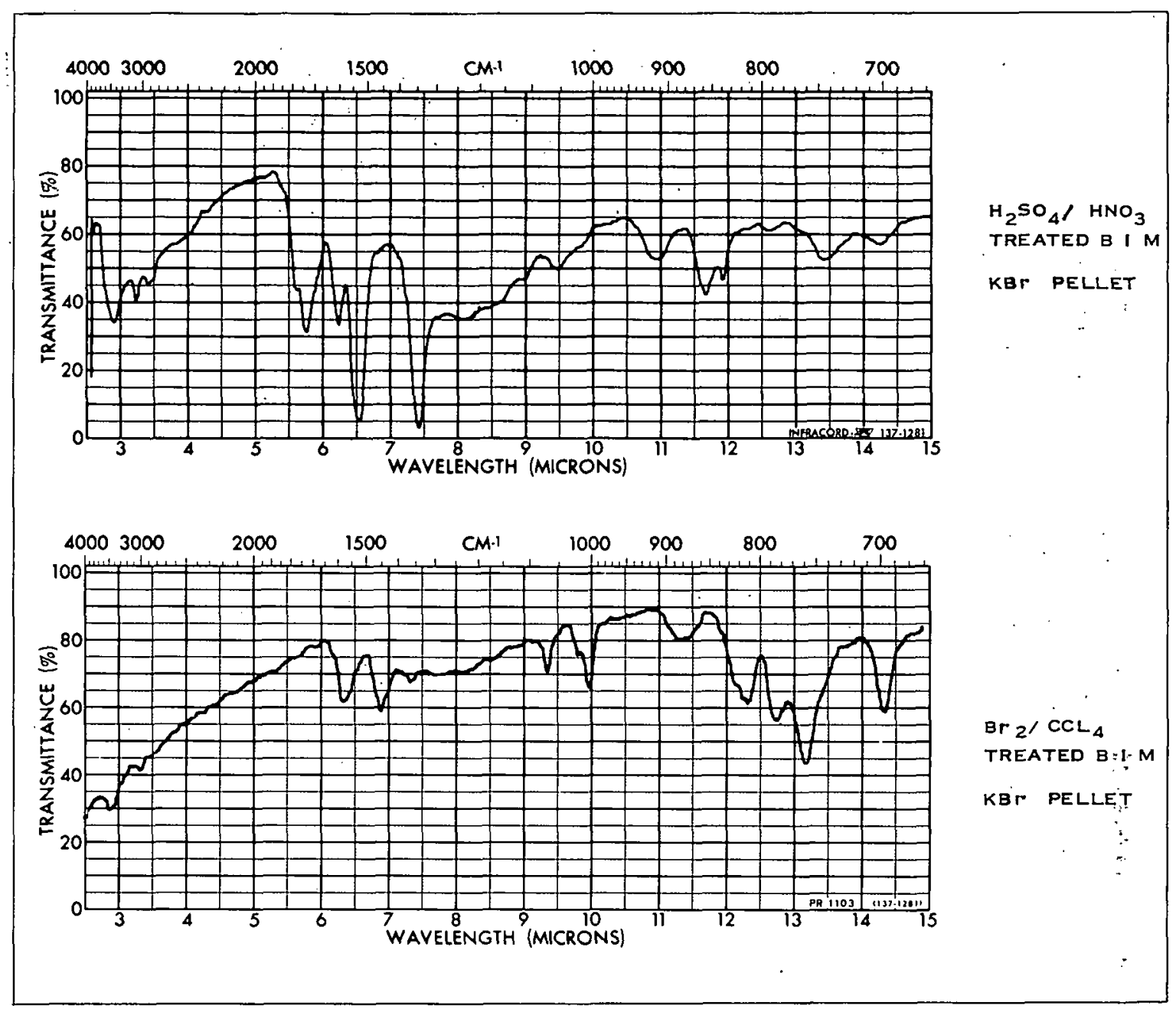

Fig. 7b Infrared spectra of $\mathrm{H}_{2} \mathrm{SO}_{4}, \mathrm{HNO}_{3}, \mathrm{H}_{2} \mathrm{SO}_{4} / \mathrm{HNO}_{3}$ or $\mathrm{Br}_{2}$-treated BIM.

For comparative purposes, 0.5-gram samples of m-terphenyl were treated in the same manner as BIM. The $\mathrm{H}_{2} \mathrm{SO}_{4}$ product was water soluble and could not be recovered. Bromine reacted only slightly. Nitric acid and $\mathrm{HNO}_{3} / \mathrm{H}_{2} \mathrm{SO}_{4}$ products were recovered in 0.9 - and 1.1-gram quantities, respectively. Their infrared spectra are shown in Figure 8.

Infrared examination showed that sulfuric acid reacted by two paths: (a) formation of sulfonic acids and (b) formation of either sulfones or sulfoxides. The latter types may not be present, however, as the bands assigned to them may correspond to fused-ring structures containing one or two adjacent protons (no more than two can be present since the 13.3- and 14.3-micron bands are not present) alșo. Some aliphatic hydroxyl groups also may be present.

Nitric and nitric/sulfuric acids gave only nitroaromatic hydrocarbons with m-terphenyl whereas with BIM a large amount of oxidation occurred as well. An aliphatic ketone structure was indicated; not of the quinoid type, however. Polyphenyl structure was still evident here. 


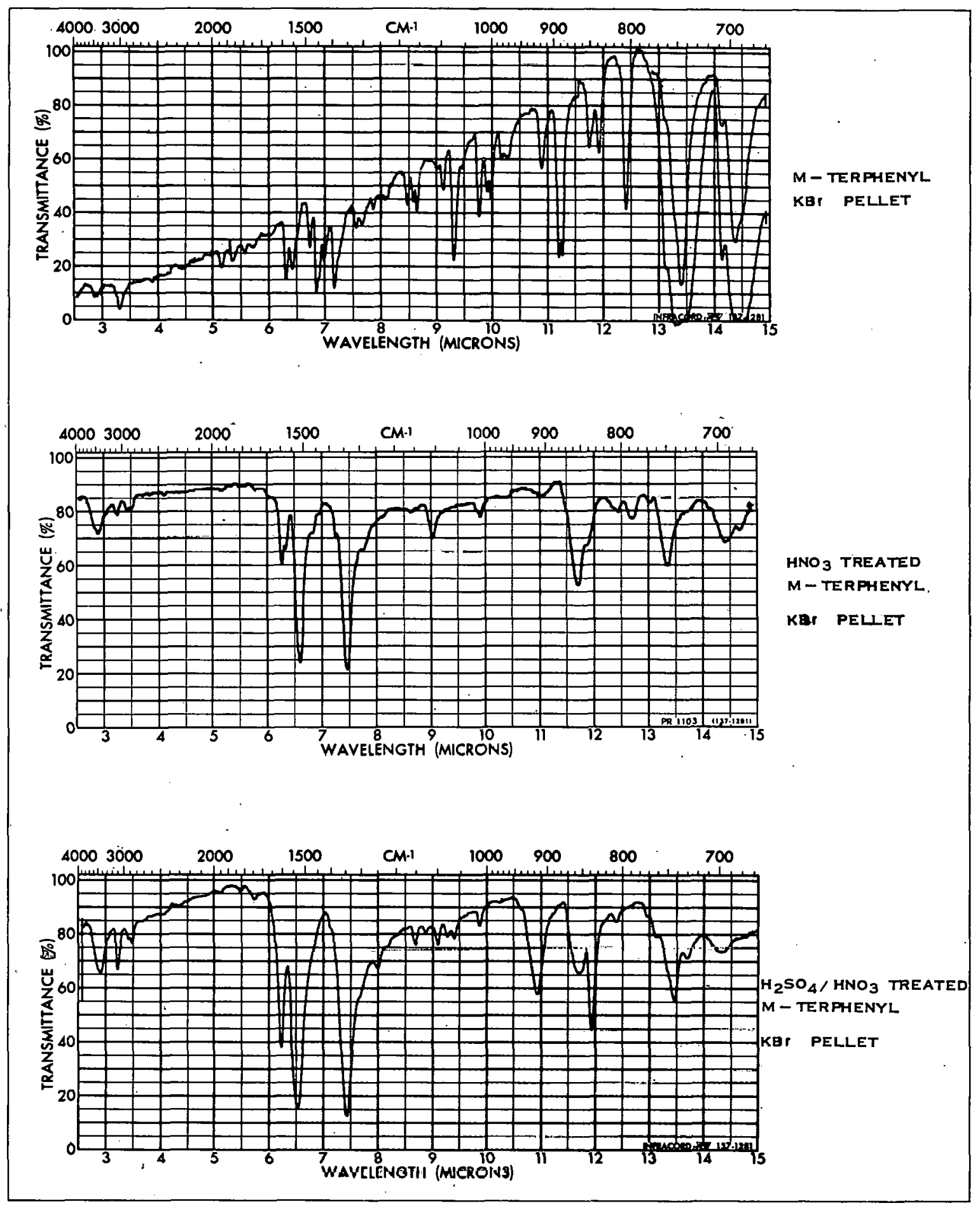

Fig. 8 Infrared spectra of $\mathrm{H}_{2} \mathrm{SO}_{4}$ and $\mathrm{H}_{2} \mathrm{SO}_{4} / \mathrm{HNO}_{3}$-treated m-terphenyl.

Bromination introduced some small new bands in the $12-$ to 13 -micron region of the spectra of BIM. An examination of the 15- to 25-micron region of the spectrum showed no characteristic carbon-bromine bands. However, elemental analysis and drying under high vacuum indicated the bromine was firmly held. Possibly the bromine was adsorbed rather than bonded. 
With certain assumptions it was possible to construct empirical formulae from the above analytical data as shown in Table XIII.

TABLE XIII

FMMPJRICAL FORMULAE OF PRODUCTS FROM REACTION

$\mathrm{OF} \mathrm{H}_{2} \mathrm{SO}_{4}, \mathrm{HNO}_{3}$, and $\mathrm{Br} 2 \mathrm{WITH}$ BIM

\begin{tabular}{lll}
\hline Treatment & & Empirical Formula \\
\hline $\mathrm{H}_{2} \mathrm{SO}_{4}$ & $\begin{array}{l}\text { All sulfur as }-\mathrm{SO}_{3} \mathrm{H} \text { and } \\
\text { excess oxygen as }-\mathrm{OH}\end{array}$ & $\mathrm{C}_{7.5} \mathrm{H}_{5.3}\left(\mathrm{SO}_{3} \mathrm{H}\right)(\mathrm{OH})_{3}$ \\
$\mathrm{HNO}_{3}$ & $\begin{array}{l}\text { All nitrogen as }-\mathrm{NO}_{2} \text { and } \\
\text { excess oxygen as }>\mathrm{C}=0\end{array}$ & $\mathrm{C}_{7.3} \mathrm{H}_{4.4}\left(\mathrm{NO}_{2}\right)(\mathrm{CO})$ \\
$\mathrm{Br}_{2}$ & - & $\mathrm{C}_{8.4} \mathrm{H}_{4.5} \mathrm{Br}^{\mathrm{Br}}$ \\
None & - & $\mathrm{C}_{7.8} \mathrm{H}_{5}$ \\
\hline
\end{tabular}

From the preceding data, it appears that considerable aromatic structure is present which accounts for normal sulfonation and nitration. Easily oxidized aliphatic structure of the type $\operatorname{Ar}\left(\mathrm{CH}_{2}\right)_{n} \mathrm{Ar}$ (where $\mathrm{n}=3$ or more) was present to obtain aliphatic ketones. Some olefinic or acetylenic unsaturation may be present which accounts for the high bromine uptake and the presence of possible hydroxyl groups from reaction with $\mathrm{H}_{2} \mathrm{SO}_{4}$.

\section{OXIDATION OF OMHE HB}

\section{$5.1 \mathrm{Na}_{2} \mathrm{Cr}_{2} \mathrm{O}_{7} / \mathrm{H}_{2} \mathrm{O}$}

A method [12] for oxidizing alkyl side chains on aromatic compounds was applied to OMRE HB.

Fifty-five grams of OMRE HB were reacted with 45 grams of $\mathrm{Na}_{2} \mathrm{Cr}_{2} \mathrm{O}_{7}$. $2 \mathrm{H}_{2} \mathrm{O}$ in $100 \mathrm{ml}$ of water in a steel bomb for 18 hours at $250^{\circ} \mathrm{C}$. The aqueous phase was decanted and the black mass was washed with water and dried. The black material was extracted in a Soxhlet unit with benzene to remove 42 grams of "unreacted" starting material. The infrared spectrum of the soluble material showed a small amount of carbonyl structure at 5.9 microns but otherwise the spectrum was identical to that of OMRE HB.

The benzene-insoluble residue, a green-black powder weighing 26 grams, was extracted with one percent $\mathrm{KOH}$, water, and acetone, and dried. The solutions from the extraction were evaporated to dryness, acidified with $\mathrm{HCl}$, and etherextracted and the ether evaporated to yield only 0.2 gram of aqueous-base soluble acids. Infrared spectra of these two fractions are shown in Figure 9. The spectrum for $\mathrm{Cr}_{2} \mathrm{O}_{3}$ also is included.

The base soluble acids have an infrared spectrum typical of aromatic acids. The residue from this extraction, on the other hand, showed a very small carbonyl 


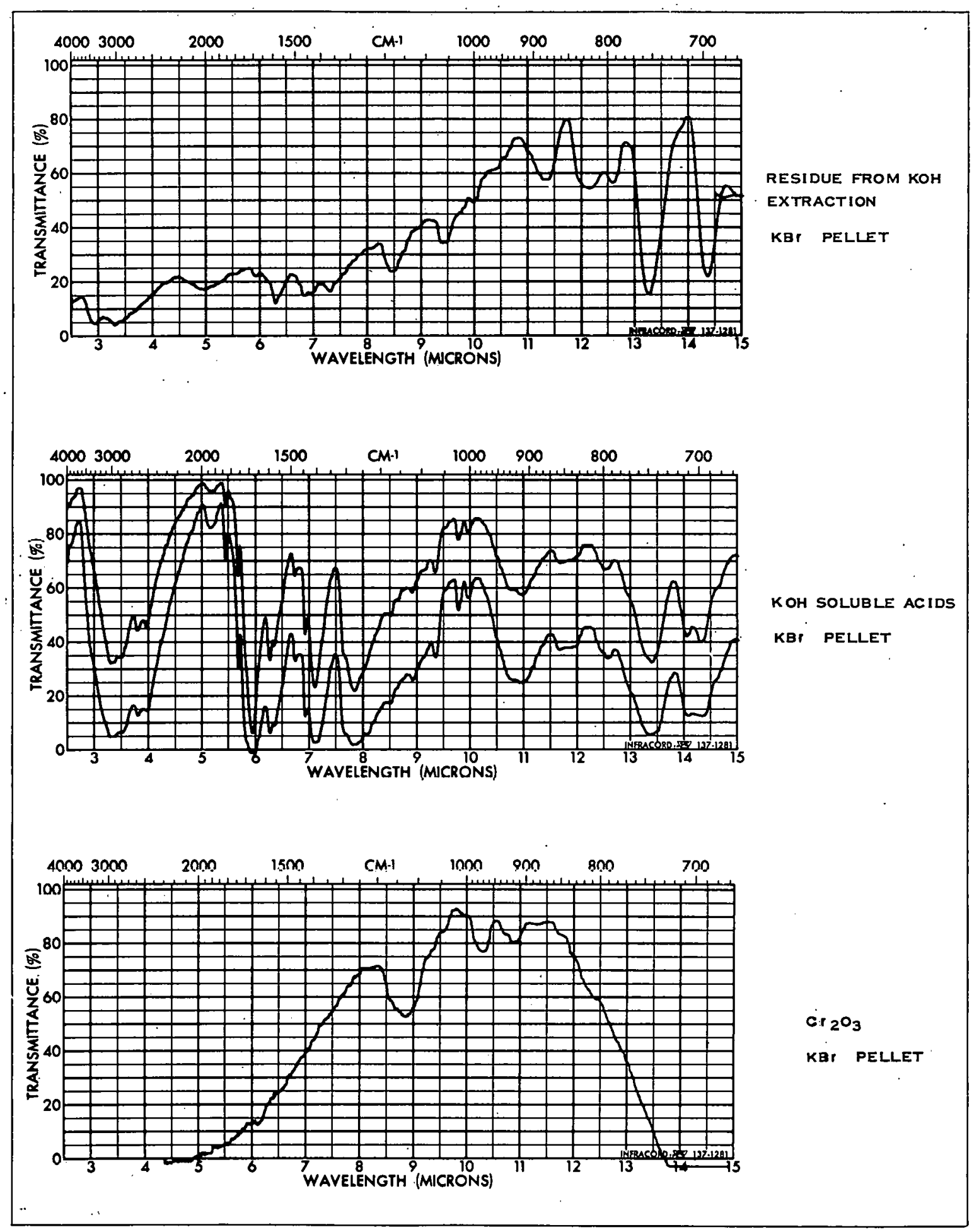

Fig. 9 Infrared spectra of $\mathrm{Na}_{2} \mathrm{Cr}_{2} \mathrm{O}_{7}$-oxidized OMRE $\mathrm{HB}$ and $\mathrm{Cr}_{2} \mathrm{O}_{3}$.

band and no appreciable amount of $\mathrm{Cr}_{2} \mathrm{O}_{3}$ appears to be present. It analyzed 59.5 percent carbon, 3.6 percent hydrogen, 7.6 percent organic oxygen, and 30.6 percent ash. Comparison with the spectrum of original OMRE HB (see Figures $1 \mathrm{a}$ and $1 \mathrm{~b}$ ) . shows two new bands present at 8.5 and 9.5 microns. To ascertain whether chromium salts had formed with any acids present in the 
oxidized OMRE HB, the base-extracted insoluble material was extracted repeatedly with $6 \underline{\mathrm{N}} \mathrm{HCl}$. When green color in the extract almost vanished, the residue was water washed and dried. Ash analysis on the material was 28.0 percent. Apparently much chromium was bound with the product, presumably as the acid salt. Since the free acid could not be obtained, no further work was performed with this system. However, the experiments indicated considerable oxidizable groups were present in OMRE HB.

\section{$5.2 \mathrm{KMnO}_{4} /$ Pyridine}

A second system examined for oxidizing OMRE $\mathrm{HB}$ was $\mathrm{KMnO}_{4}$. In order to obtain a homogeneous reaction system, pyridine with a trace of water was used as a solvent. The products were isolated by adding dilute $\mathrm{NaOH}$ to the reaction mixture, extracting with chloroform to remove "unreacted" starting material, evaporating the aqueous-pyridine phase almost to dryness, acidifying with dilute $\mathrm{H}_{2} \mathrm{SO}_{4}$, extracting with ether to recover most of the acids produced, and filtering the ether-insoluble acids to recover the remainder. Very small amounts of ether-insoluble acids were recovered and amounts are therefore not included in the data. A number of model compounds were studied in this oxidizing system to ascertain what types of functional groups would be oxidized. Table XIV shows all the reference compounds studied and the conditions used. One hundred milliliters of pyridine was used in every case. Temperature of the reactions was reflux temperature. The solutions were stirred with magnetic stirrers. The $\mathrm{KMnO}_{4}$ was not initially completely soluble in the solutions.

This system is a relatively weak oxidizing one. It attacks olefins, cycloolefins, alcohols, aldehydes, and specially activated aliphatic methylene groups but it will not attack aliphatic side chains on aromatic rings unless a second easily oxidized group also is present on the ring. Its oxidizing capabilities are considerably enhanced by addition of a small amount of aqueous alkali.

The system was subsequently applied to OMRE HB and chemically treated OMRE HB. The chemical treatments used to modify the material were as follows:

$\mathrm{H}_{2} \mathrm{SO}_{4}$ Treatment - Thirty grams of OMRE HB were dissolved in 300 $\mathrm{ml}$ carbon tetrachloride and washed with four $100-\mathrm{ml}$ portions of 96 percent $\mathrm{H}_{2} \mathrm{SO}_{4}$. Emulsions formed and heating were noted during the first two washes. The final wash was almost clear. The carbon tetrachloride layer was washed with dilute $\mathrm{NaOH}$ and water, and the carbon tetrachloride evaporated to yield 17 grams of solid analyzing 88.0 percent carbon, 5.3 percent hydrogen, 0.1 percent oxygen, 0.2 percent sulfur, and 6.6 percent chlorine. The chlorine could not be removed completely by heating at $100^{\circ} \mathrm{C}$ in vacuo for four hours. Apparently some reaction had occurred between the OMRE HB and carbon tetrachloride during $\mathrm{H}_{2} \mathrm{SO}_{4}$ extraction. This residue should be free of unsaturated structures.

Silica Gel Chromatography - Ten grams of OMRE HB were dissolved in $250 \mathrm{ml}$ of benzene and put through a column of 60 to 200 mesh silica gel. The eluate was evaporated to obtain OMRE HB which should be free of most oxygenated compounds.

Hydrogenation - Fifty grams of OMRE HB were reduced with 15 grams of reduced $\mathrm{NiO}$ on alumina ( 70 percent $\mathrm{Ni}$ in the reduced state) at 250 to $297^{\circ} \mathrm{F}$ and 1180 to 1400 psig hydrogen for 14 hours. It analyzed 93.5 percent carbon and 6.5 percent hydrogen and had a 3.8 bromine number. 
TABLE XIV

OXIDATION OF CRGAVII COMPOUNDS WITH KMnO, /PYRIDINE SYSTEM

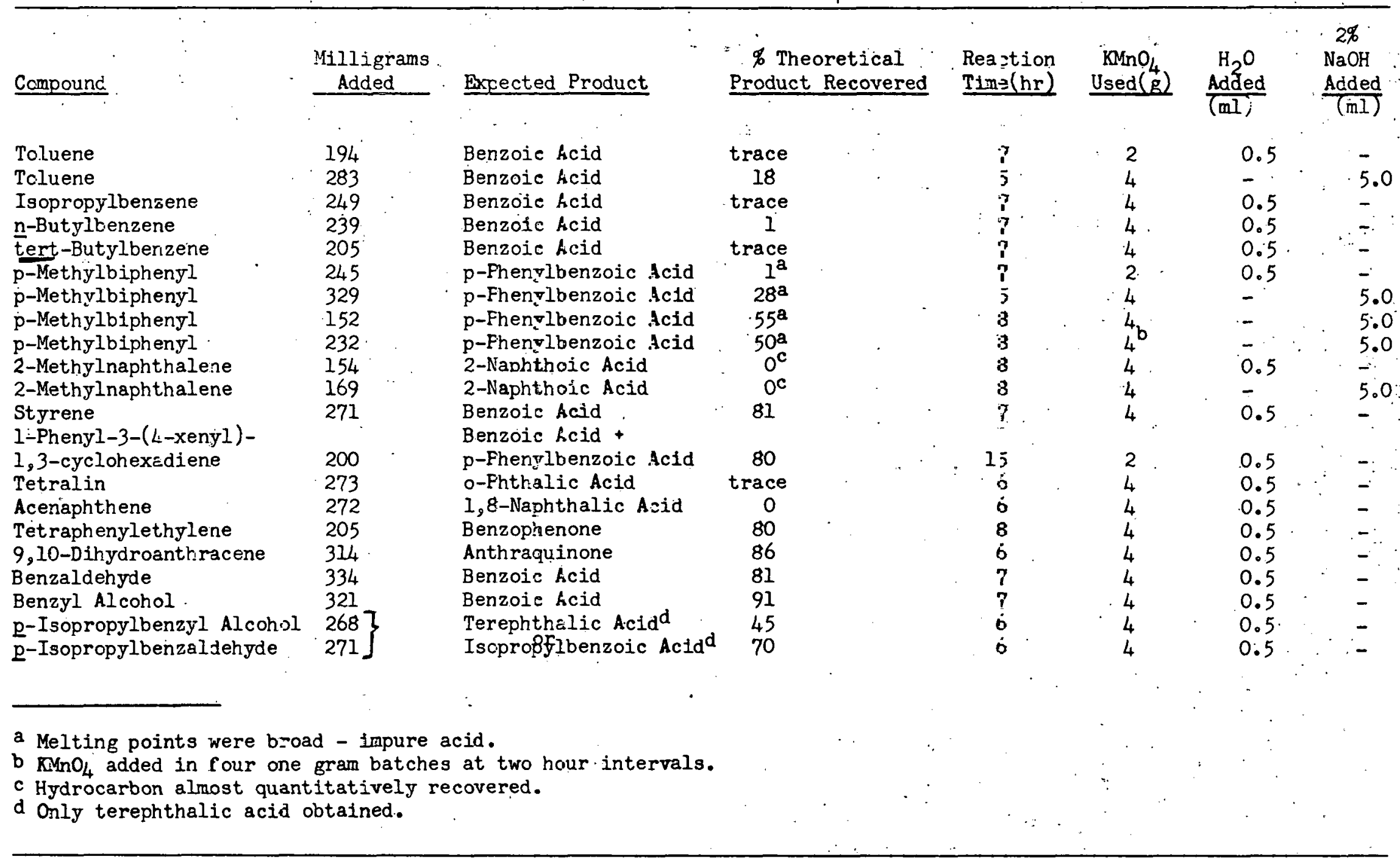


Benzene Insoluble High Boiler (BIM) - A sample of the material described in Section II, 2.3 also was oxidized in the pyridine $/ \mathrm{KMnO}_{4}$ system.

Table XV shows the data on the acids obtained from OMRE HB and the variously treated material. Four grams of $\mathrm{KMnO}_{4}$ and $0.5 \mathrm{ml}$ of water were used in all the runs except one. Reaction time was 7 to 8 hours.

A typical infrared spectrum of the acids recovered is shown in Figure 10. The spectra are practically identical for all the acids obtained.

The quantity of material used in this oxidation had a large effect on the amount of acids recovered. However, it appears that none of the treatments affected the amount of acids recovered significantly when equivalent sample weights were compared. Only including $\mathrm{NaOH}$ in the oxidation media gave a significant rise in acids obtained. BIM gave almost twice as much acids as total OMRE HB.

Empirical formulae from elemental analysis together with NMR and neutralization equivalent data roughly characterized the acids as shown in Table XVI. The acids were assumed to be monobasic because they were ether soluble.

Although the molecular weights do not agree, the main point is the generally low-molecular-weight acids obtained from OMRE HB by this mild oxidizing system. Since no low-molecular-weight alkylpolyphenyls were present in this material, "polymer" chains must have been broken to obtain these low-molecularweight acids. The results require the presence of oxidizably unstable linkages in the "polymer" chains. These linkages were stable to hydrogenation and $\mathrm{H}_{2} \mathrm{SO}_{4}$ treatment. Also, the linkages must be near the polymer chain end since monobasic acids were obtained. The linkages do not contain oxygen as elemental analysis of OMRE HB and BIM showed only traces were present. The low bromine number on OMRE HB indicates the linkages do notbrominate easily. Possibly some form of highly substituted unsaturation may be indicated since infrared and NMR spectroscopy show no evidence for the presence of olefinic hydrogen. Acetylenictype structure could be consistent with analytical data. Acetylenic compounds are formed from irradiated biphenyl [13]. A discussion of possible polymers of this type will be found in Section 8 of this report. This same reasoning must apply for the benzene-insoluble material (BIM) from OMRE HB to a larger extent since much more acidic material was obtained.

6. FILMS DEPOSITED FROM BENZENE SOLUTION OF OMRE HB AND IRRADIATED COOLANT FROM OMRE REACTOR (CORE 2 COOLANT)

As indicated in Section II, 2.1 and II, 2.2 of this report, benzene solutions of OMRE HB deposited an insoluble film on the glass surfaces of the container.

Since this film may be associated with film formation in atomic reactors, it was studied to some extent. An irradiated polyphenyl coolant was studied in addition to OMRE HB. This coolant was material removed from the OMRE reactor after $904 \mathrm{Mwd}$ exposure, containing approximately 23 percent material boiling above $\mathrm{p}$-terphenyl, 67 percent terphenyls, and 10 percent material boiling below the terphenyls. It will be designated Core 2 Coolant in the discussion. This 


\section{TABLE XV}

ACIDS OBTAINED BY $\mathrm{KMnO}_{4}$ / IYRIDINE JXIDATION OF OINRE HB AND TREATED OMRE HCB

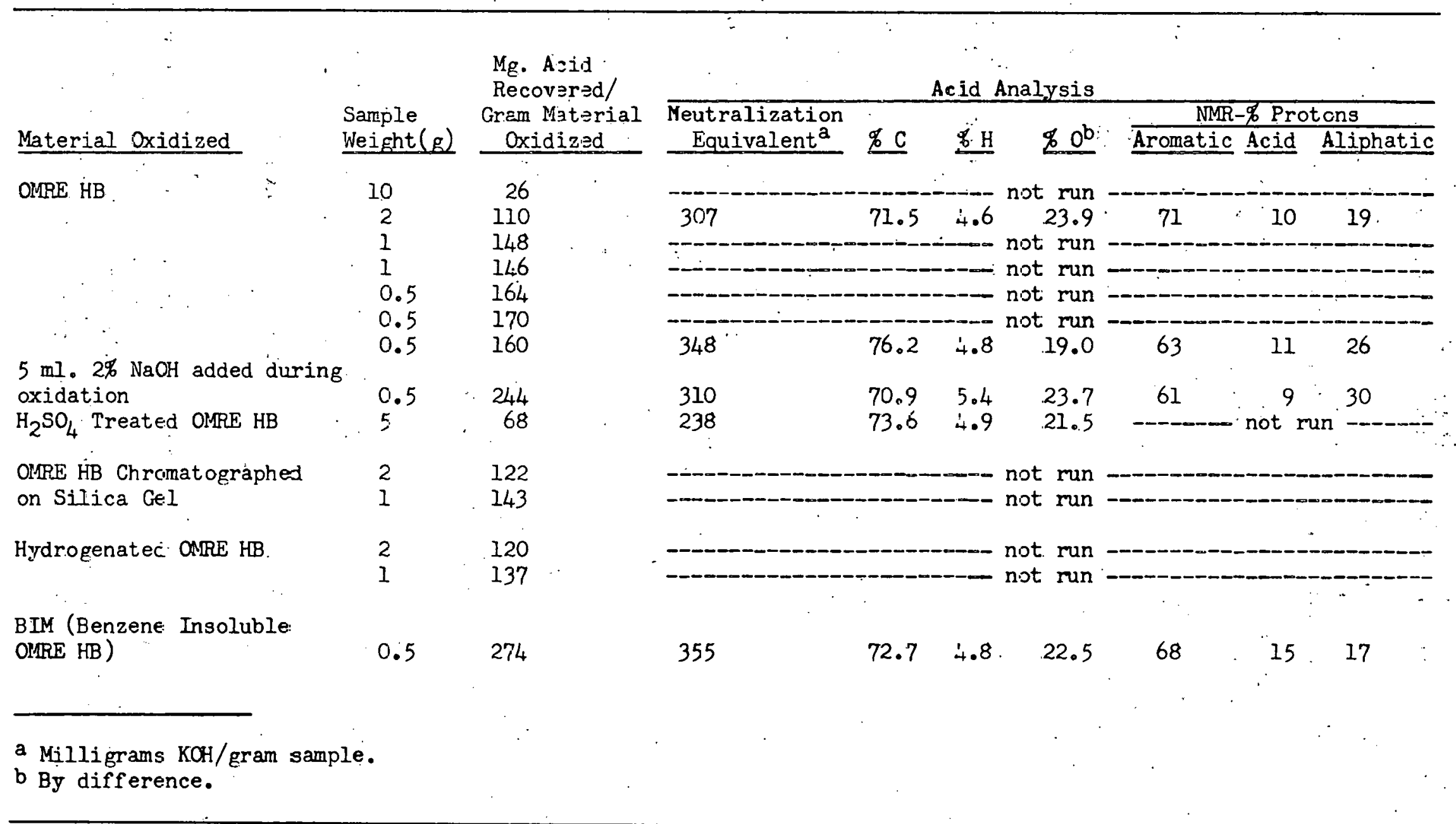




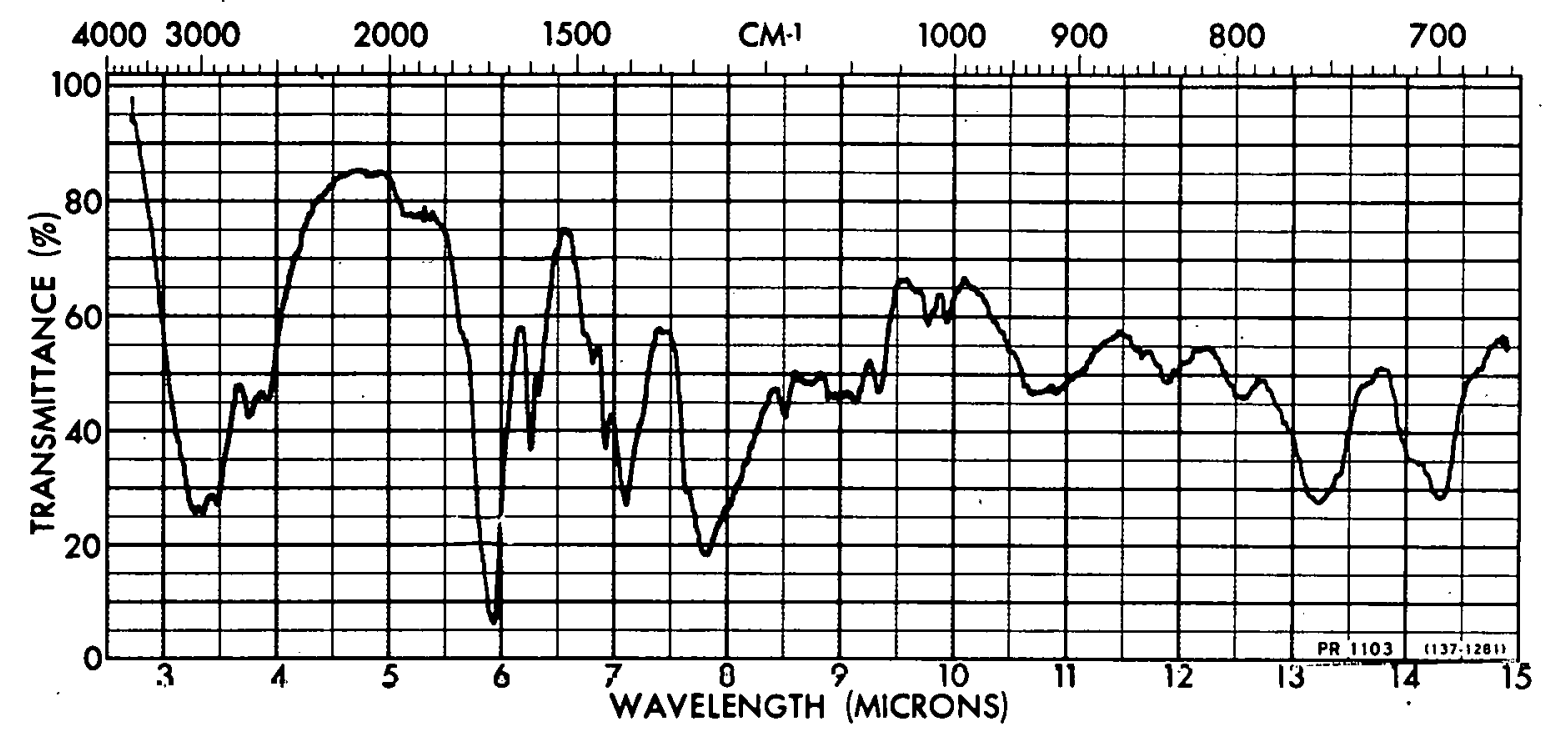

Fig. 10 Typical infrared spectrum of acids recovered from $\mathrm{KMnO}_{4}$ /pyridine oxidation of OMRE HB or treated OMRE HB or BIM.

Formula From Elemental Analysis - $\left(\mathrm{C}_{\mathrm{q}} \cdot 0^{\mathrm{H}}\left(\mathrm{G}_{2} \mathrm{O}_{2}\right)_{\mathrm{n}}\right.$

Molecular Weight From Neutralization Equivalent - 183

Molecular Weight From NMR Data - 210

"Average" Struture from NMR -

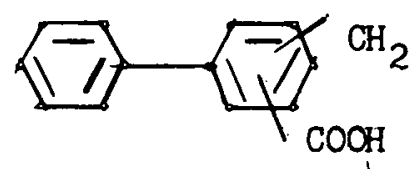

coolant deposited a film from benzene solution, although not as heavily as OMRE HB.

Initially, Core 2 Coolant was treated in various ways in an attempt to destroy its film-forming capabilities. A sample in benzene was chromatographed on silica gel to remove oxygen compounds and benzene-insoluble material. A second sample was diseolved in 10 pereent benzene solution and washed with $\mathrm{H}_{2} \mathrm{SO}_{4}$ to remove oxygenated and olefinic compounds. It was finally washed with dilute $\mathrm{NaOH}$ and water, and dried. A third sample was heated to $325^{\circ} \mathrm{C}$ while air was bubbled through it for seven hours. Also, several tests were run in which additives were included with untreated Core 2 Coolant in the benzene solution film experiments. Table XVII shows the results of this work. Also included in the table are samples of OMRE HB and hydrogenated OMRE HB (as described 


\begin{tabular}{|c|c|c|c|c|}
\hline \multirow{2}{*}{$\begin{array}{l}\text { Treatment of Material } \\
\text { Tested/Additive Included }\end{array}$} & $\begin{array}{l}\text { Weight of } \\
\text { Material } \\
\text { Used (g) }\end{array}$ & $\begin{array}{l}\text { Volume of } \\
\text { Benzene } \\
\text { Used (ml) }\end{array}$ & \multirow{2}{*}{$\begin{array}{l}\text { Wt/Vol } \\
.(\mathscr{z}) \\
\end{array}$} & \multirow{2}{*}{$\begin{array}{c}\text { Film } \\
\text { Produced }\end{array}$} \\
\hline & \multicolumn{2}{|c|}{ Core 2 Coolant } & & \\
\hline $\begin{array}{l}\text { None/None } \\
\text { Chromatographed on Silica }\end{array}$ & 10) & 250 & 4 & yes \\
\hline Gel/None & 10 & 250 & 4 & yes \\
\hline $\begin{array}{l}\mathrm{H}_{2} \mathrm{SO}_{4} \text { Washed/None } \\
\text { Treated with Air/None }\end{array}$ & $\begin{array}{l}5 \\
5\end{array}$ & $\begin{array}{l}250 \\
100\end{array}$ & $\begin{array}{l}2 \\
4\end{array}$ & $\begin{array}{l}\text { no } \\
\text { no(Sludge in } \\
\text { bottom?) }\end{array}$ \\
\hline $\begin{array}{l}\text { None/0.1 gram Diphenyl- } \\
\text { picrylhydrazyl } \\
\text { None } / 6 \text { drops } B r_{2} \\
\text { None/6 drops } n-1 \text { - } 0 \text { ecyl Mercaptan } \\
\text { None/0.1 gram } 1,4 \text {-Naphthoquinone }\end{array}$ & $\begin{array}{l}5 \\
5 \\
5 \\
5\end{array}$ & $\begin{array}{l}100 \\
100 \\
100 \\
100\end{array}$ & $\begin{array}{l}5 \\
5 \\
5 \\
5\end{array}$ & $\begin{array}{l}\text { yes } \\
\text { no(very light }) \\
\text { yes } \\
\text { yes }\end{array}$ \\
\hline \multicolumn{5}{|c|}{ OMRE HB } \\
\hline $\begin{array}{l}\text { None/None } \\
\text { Hydrogenation/None }\end{array}$ & $\begin{array}{r}10 \\
5\end{array}$ & $\begin{array}{l}100 \\
100\end{array}$ & $\begin{array}{r}10 \\
5\end{array}$ & $\begin{array}{l}\text { yes } \\
\text { no. }\end{array}$ \\
\hline
\end{tabular}

in Section II, 5.2) which were treated by the same procedure. All tests were run for four days except with hydrogenated OMRE HB which ran for two months.

Hydrogenation, sulfuric acid, air, and possibly bromine treatment all destroyed the film-forming capabilities of the two materials studied. The presence of benzene-insoluble material, oxygenated compounds, free radical scavengers, and radical reaction inhibitors had no effect on the reaction. All the treatments which had an inhibitory action were with materfals that react with non-aromatic unsaturated linkages. It is quite possible that such species are present in the reactor coolant materials. Therefore, this class of compoind may be a precursor for the sort of film formation shown by this test.

More quantitative and qualitative information was developed on these films hy preparing some on a larger scale. Twenty-five grams of UIVRE HB and of Core 2 Coolant were dissolved in $500-\mathrm{ml}$ portions of benzene and these solutions allowed to stand for six weeks in glass flasks. Then the solutions were decanted and the films washed thoroughly with benzene. They were removed from the flasks by scraping, washing with hot water, and finally washing with hot, dilute $\mathrm{NaOH}$. After suitable water washing they were dried, weighed, and analyzed. The decanted benzene solutions contained insoluble sludge. The solutions were allowed to stand for two weeks further in new glass flasks. No film deposited from either sample on the walls of the flask. The sludge which was present in the bottom of each flask was recovered by centrifugation, washed thoroughly with benzene, dried, and analyzed.

The analyses on these four products are shown in Table XVIII.

Infrared spectra on the four materials are shown in Figures 11a and 11b. 
TABLE XVIII

ANALYSIS OF FILMS AND INSOLUBLE SLUDGE DEPOSITED

FROM BENZENE SOLUTIONS OF OMRE HB AND CORE 2 .COOLANT

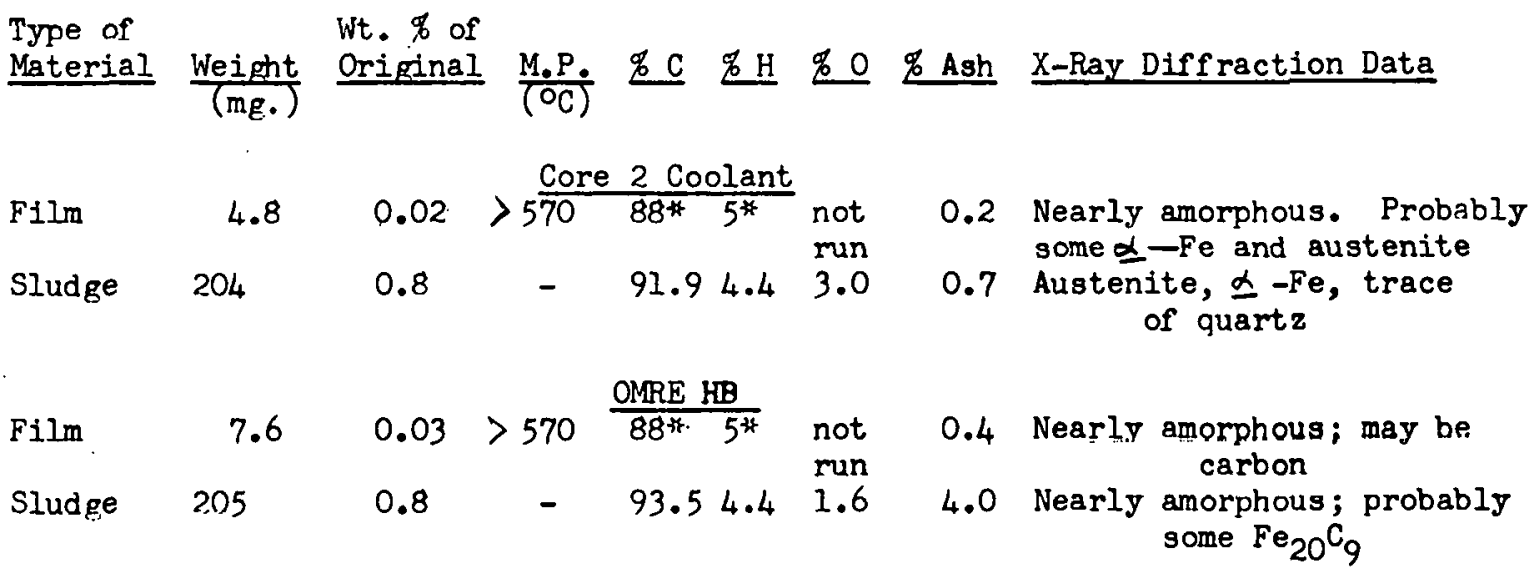

*Samples too small for accurate analyses.

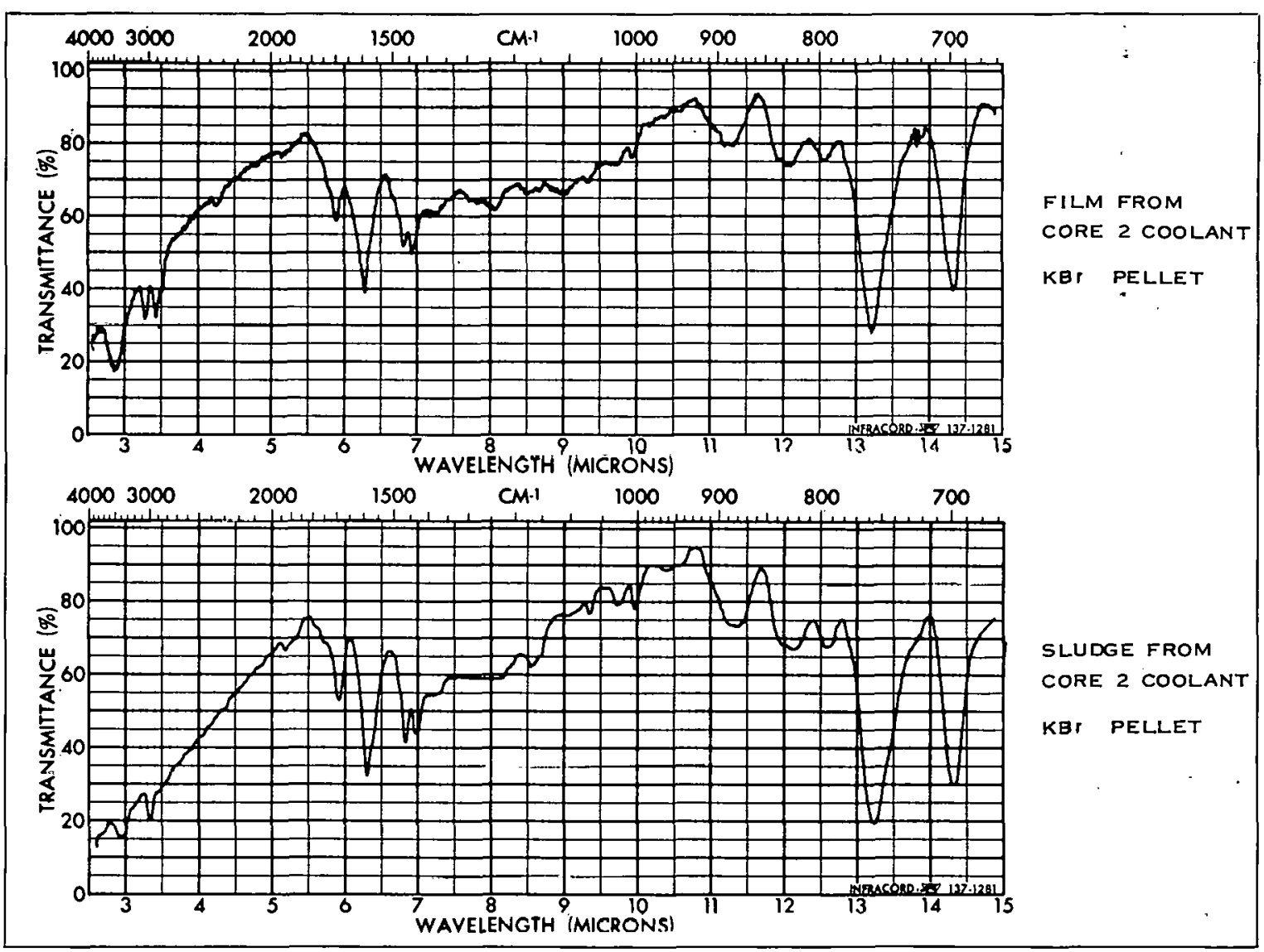

Fig. 11a Infrared spectra of film and sludge deposits from benzene solutions of OMRE HB and Core 2 coolant. 


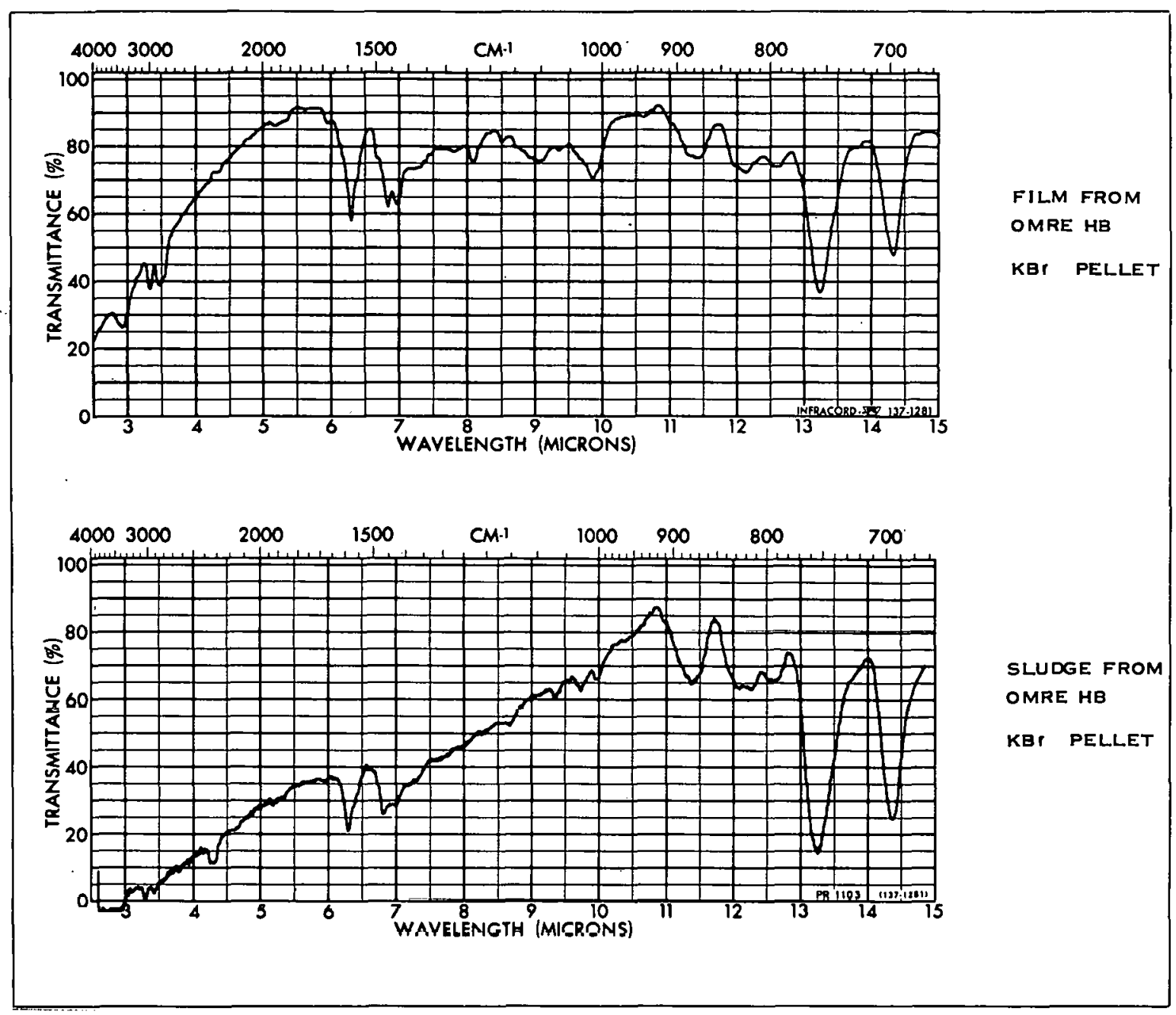

Fig. $11 \mathrm{~b}$ Infrared spectra of film and sludge deposits from benzene solutions of OMRE HB and Core 2 coolant.

The main difference noted between the films and sludge is that the ash content was higher for the sludge. The infrared spectra showed considerable carbonyl present in the Core 2 Coolant products which was not present in the OMRE HB products. The carbonyl also was present in total Core 2 Coolant so it was not formed with the film and sludge. More aliphatic structure was indicated in both films than in the sludges. Polyphenyl structure was present in considerable amount in all cases.

Material which precipitated from benzene solutions of irradiated polyphenyl coolants may correlate with films deposited in atomic reactors on metal surfaces. If a benzene film or sludge test could be correlated with the fouling potential of a coolant, a rapid means would be available for checking the reactor coolant fouling tendency.

Static pyrolytic film tests indicated that coolant which contained benzeneinsoluble components gave more fouling [14]. Also, higher fouling was observed with higher-molecular-weight fractions of the high boiler. Experiments with benzene solutions were undertaken to correlate solution tests with pyrolytic tests in order to develop a rapid method for determining coolant fouling potential. 
The test procedure involved placing the benzene solution in a colorimeter tube, stoppering the tube, allowing it to stand at room temperature for a given time, pouring off the solution, rinsing three times with benzene, and measuring the optical density on a Klett-Summerson Photoelectric colorimeter with red, green, and blue filters. The optical density was measured in arbitrary units.

An experiment was conducted on various molecular-weight fractions from OMRE HB. The high boiler had been sublimed and the molecular weight of each fraction determined. One-tenth-gram samples of each fraction were placed in $11.5 \mathrm{ml}$ of benzene and allowed to stand in colorimeter tubes 46 hours.

The data are shown in Table XIX.

\section{TABLE XIX}

OPTICAL DENSITY OF FIIM FROM BENZENE FOR VARIOUS FRACTIONS OF OMRE HB

\begin{tabular}{|c|c|c|c|}
\hline & Optical & Density (Arbitrary & Units) \\
\hline Molecular Weight & Red & Green & Blue \\
\hline 572 & 36 & 67 & 120 \\
\hline 645 & 37 & 70 & 129 \\
\hline 736 & 37 & 70 & 131 \\
\hline 804 & 46 & 89 & 168 \\
\hline 962 & 51 & 102 & 188 \\
\hline 1273 & 55 & 110 & 206 \\
\hline 1290 & 69 & 140 & 260 \\
\hline
\end{tabular}

Excellent correlation was obtained with the molecular weight of the fraction and also the fouling tendency in the static film apparatus.

The effect of time was studied when a 1.13 weight percent solution of Core 2 Coolant in benzene was run. The solution was filtered and placed in 12 colorimeter tubes. The tubes were allowed to stand for various intervals of time and the optical density determined. Table XX presents the data.

A plot of optical density vs time is shown in Figure 12. In Figure 13, a firstorder plot was obtained by graphing log (160 optical density) vs time.

In static film tests, plotting the log (percent power loss) against time gave a straight line [15]. Similar plots with the benzene solution data gave a slightly sinusoidal curve. Thus, film deposition in both cases followed similar rate equations.

As mentioned previously, in addition to film formation a sludge formed in benzene solutions of coolant and high boiler. The amount of sludge exceeded the amount of film. The benzene-insoluble sludge precipitated rapidly compared to film formation on glass. Table XXI shows the results from centrifuging a 4.3 percent benzene solution of Core 2 Coolant. The solution was filtered 
TABLE XX

OPTICAL DENSITY OF FILMS FROM BENZENE SOLUTION OF CORE 2 COOLANT

\begin{tabular}{|c|c|c|c|c|}
\hline \multirow[b]{2}{*}{ Time (hr) } & \multicolumn{3}{|c|}{ Optical Density } & \multirow[b]{2}{*}{$\log (O D \propto O D t) *$} \\
\hline & Red & Green & Blue & \\
\hline 4.25 & 0.5 & 6 & 16 & 2.16 \\
\hline 6.33 & 4.5 & 9 & 22 & 2.14 \\
\hline 8.92 & 7.0 & 16 & 36 & 2.09 \\
\hline 21.92 & 16.5 & 33 & 62 & 1.99 \\
\hline 30.00 & 21.5 & 46 & 75 & 1.93 \\
\hline 46.17 & 29.5 & 58 & 103 & 1.76 \\
\hline 55.33 & 38 & 68 & 113 & 1.67 \\
\hline 94.08 & 51 & 86 & 140 & 1.30 \\
\hline 118.58 & 48 & 89 & 148 & 1.08 \\
\hline 142.16 & 53 & 35 & 153 & 0.85 \\
\hline $\begin{array}{l}\text { * Data fr } \\
160 \text { (li }\end{array}$ & ilte: & optica & $\begin{array}{l}y \text { in } \\
y \text { at }\end{array}$ & $\begin{array}{l}\text { y units; } O D \infty= \\
\text { me }\end{array}$ \\
\hline
\end{tabular}

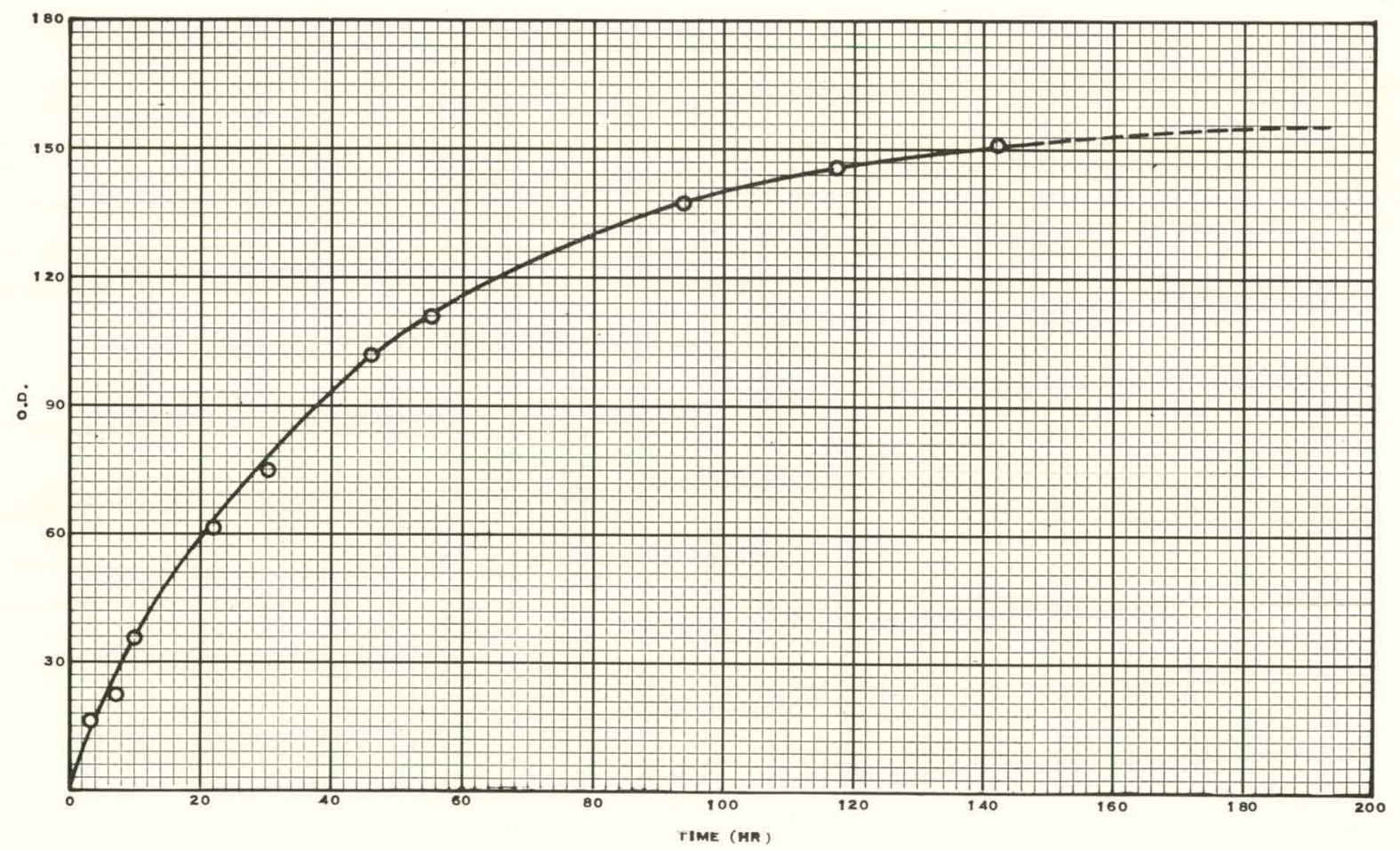

Fig. 12 Optical density of film vs time (data from Table I). 


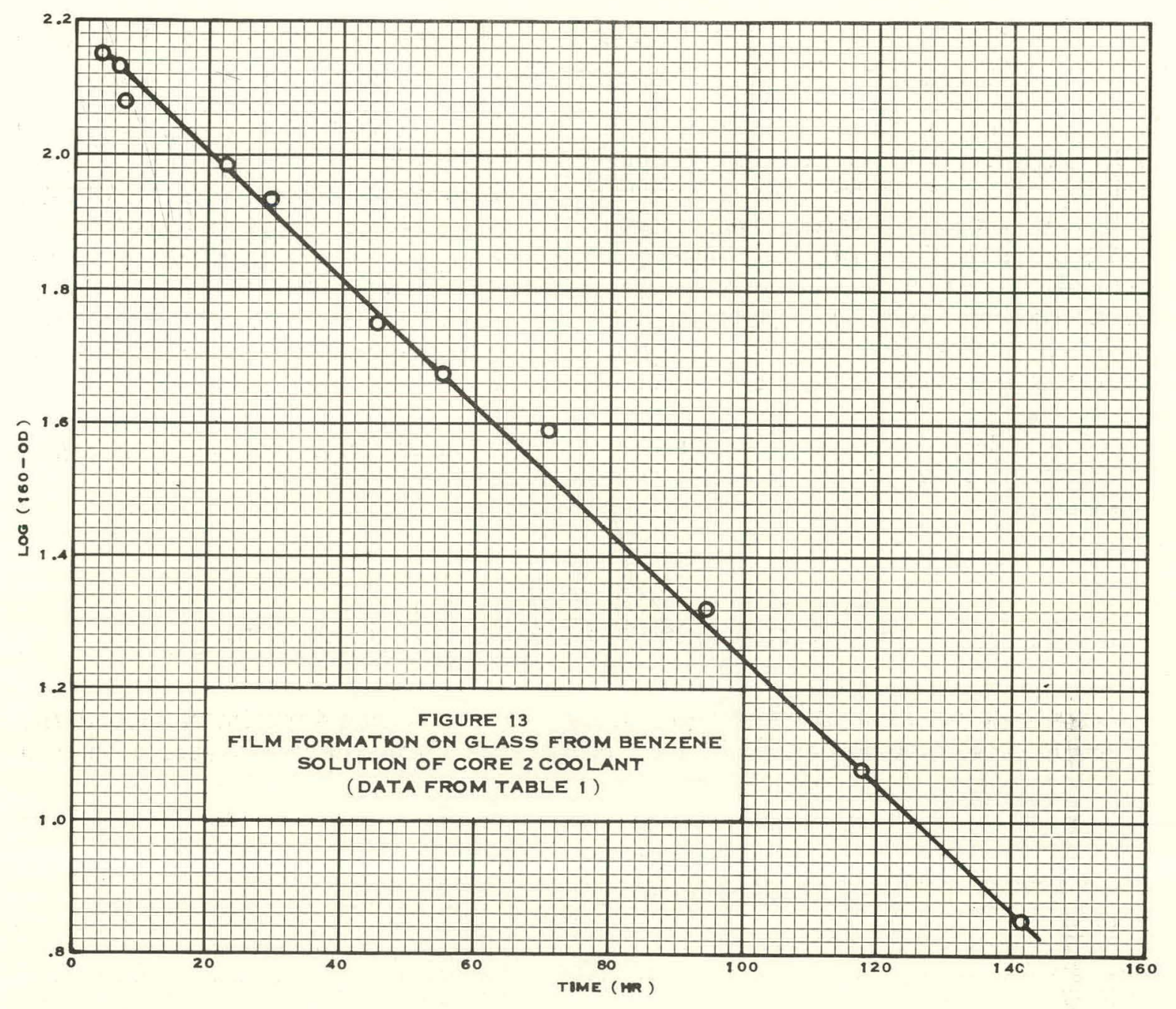

Fig. 13 Film formation on glass from benzene solution of Core 2 coolant (data from Table I).

CENTRIFUGATION OF CORE 2 COOLANT IN BENZENE

$\begin{array}{cc}\begin{array}{c}\text { Time before } \\ \text { Centrifuging }(\mathrm{hr})\end{array} & \text { Precipitate }(\mathrm{mg}) \\ 0.5 & 41.3 \\ 20.3 & 51.0 \\ 91.5 & 58.3 \\ 117.0 & 59.2\end{array}$


through Whatman No. 1 paper into $200-\mathrm{ml}$ centrifuge jars. The jars were centrifuged after various times.

The data in Table XXI show that the sludge formed quickly and increased only slightly with time. The sludge and benzene-insoluble film are probably related to a common precursor. The sludge probably represented insoluble, colloidal polymer which was formed from the unsaturated material in the coolant. The film probably was formed by polymerization of the same unsaturated materials in the benzene solution. This polymerization resulted in a high-molecular-weight, cross-linked material which became insoluble. In other words, the sludge represented material previously polymerized in the coolant while the film was formed in solution.

Both the sludge and the film should be investigated further in an effort to establish a test for the fouling potential of a reactor coolant.

7. COMPOSITION OF HIGH BULLRS

FORMED FROM IRRADIATED BIPHENYL AND O-TERPHENYL

Samples of biphenyl and o-terphenyl were electron-irradiated for 39 and 14 hours, respectively, at $600^{\circ} \mathrm{F}$ and the products distilled and analyzed as shown in Table XXII.

TABIE XXII

ANALYSIS OF DISTILTED CUIS FROM

ELECTRON-IRRADIATED BIPHENYL AND O-TERPHENYL

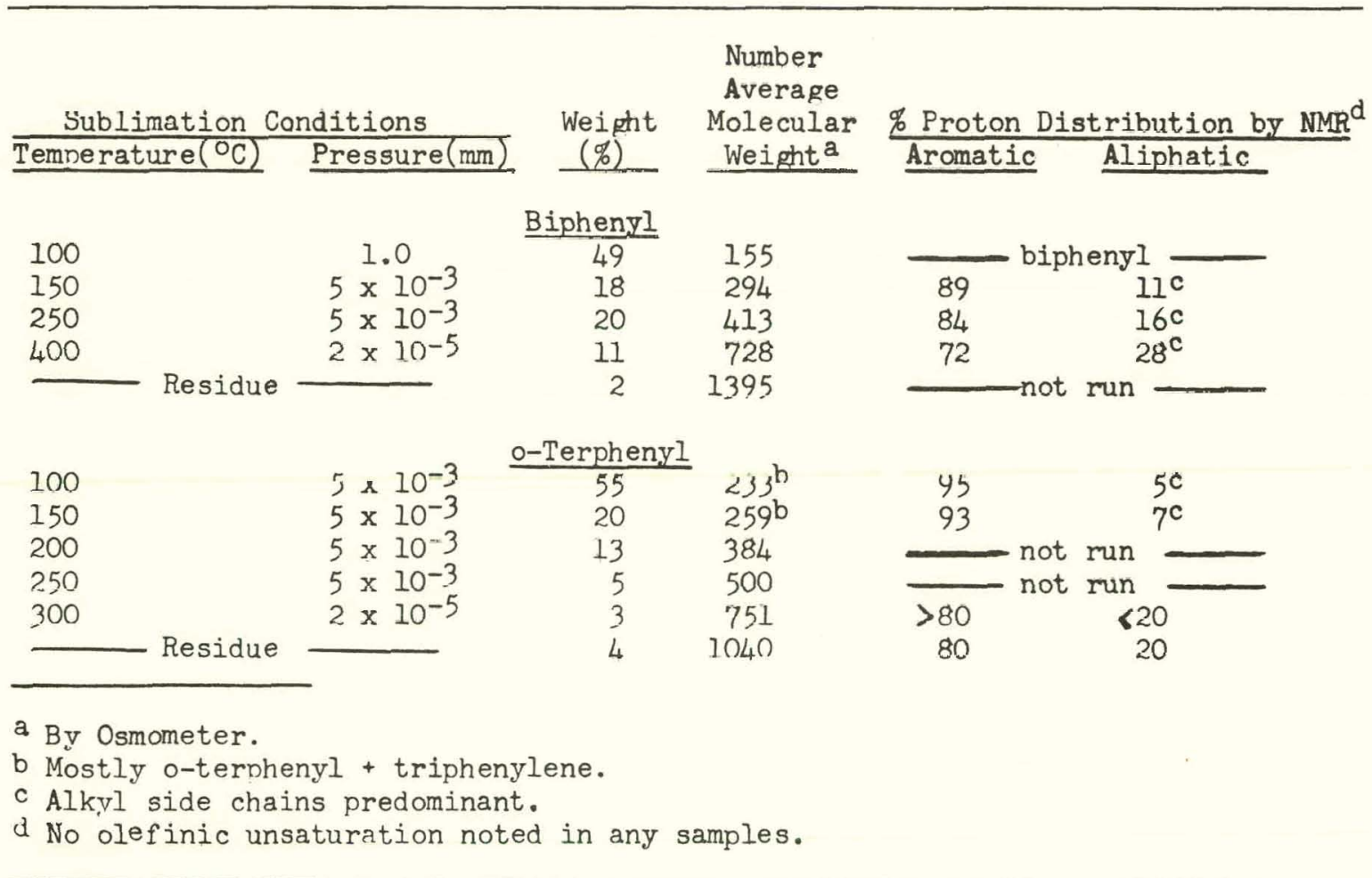


In both series, the higher-molecular-weight fractions contained more aliphatic protons. These protons were present predominantly in alkyl side chains. Since alkyl side chains necessarily infer ring cleavage during irradiation, these cleavage products probably polymerized to the high-molecular-weight compounds. Acetylenic species would be one type of product resulting from ring opening. Polymerization of these species will be discussed more fully in the next section.

Oxidation of the biphenyl fractions with $\mathrm{KMnO}_{4} /$ pyridine by the method described in Section II, 2.2 showed that the acid yield increased with molecular weight of the fraction. These acids were of the same low molecular weight type reported earlier. Therefore they arose from chain scission. These conclusions parallel those found in the work on $\mathrm{KMnO}_{4} /$ pyridine oxidation of OMRE $\mathrm{HB}$ discussed in Section II, 2.2.

\section{SPECULATIONS ON UNSATURATED SPECIES PRESENT IN IRRADIATED TERPHENYLS}

Both olefinic and acetylenic linkages can easily be produced while polyphenyls are being irradiated. Olefins may result by simple partial ring hydrogenation since hydrogen is the major gaseous product of this radiation. Also, they may form by activaled polyphenyl radicals or ions attacking polyphenyl molecules and subsequent disproportionation. Acetylenic linkages may arise from ring opening followed by loss of an unsaturated hydrocarbon fragment. In the latter case some of these acetylenic molecules would then presumably polymerize to higher-molecular-weight "polymers" of non-polyphenyl types with conjugated dienic bonds and some free acetylenic bonds. Evidence for the polyacetylenic types was presented earlier in this report. A paper by Shantarovich [16] describes polymers obtained from phenylacetylene (molecular weight approximately 1000) which are compared in Table XXIII with OMRE HB.

Item 6 in Table XXIII particularly fits a poly(phenylacetylene)-type structure as being present in OMRE HB. As mentioned earlier in this report, it is the logical source of low-rnolecular-weight monobasic acids. Alkylpolyphenyls and cyclohexane derivatives should give higher-molecular-weight polybasic acids. Both acetylenic and cyclohexadiene derivatives could give the monobasic acids obtained. However it is unlikely the cyclohexadienic-type compounds would remain under high-temperature reactor conditions without polymerizing to highermolecular-weight cyclohexene-containing materials.

If poly(phenylacetylene)-like structures are present in high boiler, they would arise initially as shown in Figure 14 from the terphenyls (acetylene not shown).

A polyacetylenic structure from these products would give a predominantly linear polymer. However, the presence of small amounts of diacetylenic product could quite easily lead to eventual crosslinking and hence insolubilization (film). 
COMPARISON OF PROPERTIES OF OMRF HB AND POLY(PHENYLACETYLENE)

\section{OMRE HB}

(1) Distillation yields yellow, orange, then red products as higher temperatures are reached. Pot residue contains increased amount of berzene insoluble material.

(2) Paramagnetic, benzene-insoluble portion particularly - not due to inorganic components.

(3) $\mathrm{H}_{2} \mathrm{SO}_{4}$ gives vigorous reaction with $\mathrm{HCCl}_{3}$ solution, removing large amount of black material and leaving a light brown ofl behind, in the $\mathrm{HCCl}_{3}$ layer.

(4) Bromine No. I

(5) Hydrogenation proceeded only partially, perhaps with a relatively reactive species.

(6) Pyridine/ $\mathrm{KMnO}_{4}$ oxidation - gave large amount of $\phi_{1-3} \mathrm{COOH}$. Residue from extraction of high boiler with $\mathrm{H}_{2} \mathrm{SO}_{4}$ gave much less acids on oxidation.

\section{Poly(phenylacetylene)}

Heating causes color to change from yellow to red to black and finally jields solvent-insoluble material.

Becomes highly paramagnetic as polymer is heated to higher and higher temperatures.

$\mathrm{H}_{2} \mathrm{SO}_{4}$ would undoubtedly react vigorously' with the polymer.

? (May be like $\phi_{2} \mathrm{C}=\mathrm{C} \phi_{2}$, which doesn't brominate at the double bond.)

? (Should hydrogenate readily at the olefinic bonds.)

Should oxidize readily to glve $\varnothing \mathrm{COOH}$ and benzil.

\section{$\underline{0-\phi_{3}}$}

( $\mathrm{m}-$ and $\mathrm{p}-\dot{\phi}_{3}$ 's are the. same except no $\phi \mathrm{C} \equiv C \phi$ and position of $\mathrm{C} \equiv \mathrm{CH}$ will be $m$ - and pin last two equatiurs)
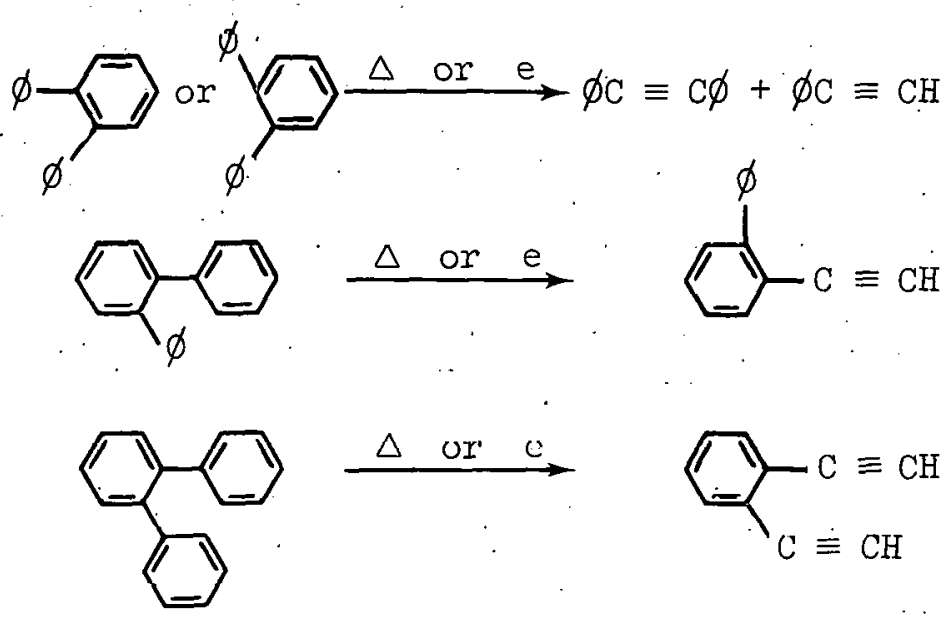

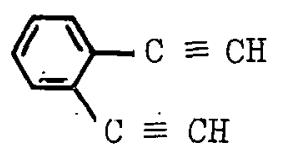

Fig. 14 Acetylenic compounds from terphenyls. 


\section{CONCLUSIONS}

Partial characterization of the high-boiling materials produced by irradiating biphenyl and the terphenyls has been accomplished. The overall product contained considerable material with 2000 molecular weight or greater. The highermolecular-weight fractions contained more aliphatic protons (mostly in aliphatic side chains) than the lower fractions. This suggests ring opening occurred followed by polymerization of the reactive fragments formed. Heating the highboiling components at $380^{\circ} \mathrm{C}$ in vacuo caused a considerable change in the amount of benzene-insoluble material present. This indicated that some reactive species were present which remained stable during storage at ambient temperature. These benzene-insoluble materials appeared to contain fused rings and alkyl side chains as well as polyphenyl structure. Some evidence was presented that stable aliphatic unsaturated linkages, perhaps acetylenic, were present in OMRE $\mathrm{HB}$ to serve as a precursor for the benzene-insoluble fraction.

Solvent fractionation techniques were rather unsuccessful in fractionating OMRE $\mathrm{HB}$ into various molecular-weight fractions, because solubility is a function of both molecular weight and structure. This sort of fractionation proved more successful on the residue from flashed OMRE HB.

Deposition of benzene-insoluble material was studied extensively. This phenomenon may serve as a measure of the film-forming capabilities of a coolant in a reactor. Further correlation work will be required to test this conclusion.

The high amounts of chlorine found in the benzene-insoluble material in OMRE $\mathrm{HB}$ and also in the highest-molecular-weight benzene-soluble fractions may be connected with film-forming capabilities of these fractions.

Oxidation of materials with $\mathrm{KMnO}_{4}$ may be modified by conducting the reaction in pyridine with no inorganic base present. Under these conditions, oxidation was somewhat selective; the oxidizing potential of the permanganate was not as great as usual. Further work is needed on this system to determine why alkyl side chains on aromatic rings are not oxidized unless an additional easily oxidizable group is present.

Characterization of high-boiling components found in OMRE HB was exceedingly difficult due to their complex structure. However, some added knowledge has been accumulated in this work. 


\section{REFERENCES}

1. T. H. Bates et al, The Radiation and Thermal Stability of Some Potential Organic Moderator-Coolants. Part I. Electron Irradiation of p-Terphenyl and Santowax R, AERE-C/R-2121 (1957).

2. T. H. Bates et al, The Radiation and Thermal Stability of Some Potential Organic Moderator-Coolants. Part II. Pile Irradiation of Para-Terphenyl and Santowax R, AERE-C/R-2185 (July 1959).

3. T. H. Bates et al, The Radiation and Thermal Stability of Some Potential Organic Moderator-Coolants. Part V. Pile and Electron Irradiation of Biphenyl, Orthoterphenyl, Metaterphenyl, and Pile Irradiation of Santowax $\mathrm{R}$ to High HBR Content, AERE-R-3743 (March 1962).

4. E. L. Colichman, R. H. Gercke, Radiation Stability of the Terphenyls and other Polyphenyl Materials as Measured by Gas Evolution, NAA-SR1288 (June 15, 1955).

5. R. A. Baxter, Low Boilers in OMRE Coolant, NAA-SR-Memo-3317 (December $31,1958)$.

6. H. M. Gilroy, Analysis of OMRE Waste Gas, NAA-SR-4130 (January 26, 1960).

7. R. T. Keen et al, Radiolysis Products of Polyphenyl Coolants. Part 1. In-pile Loop Irradiations, NAA-SR-4355 (March 30, 1962).

8. C. $\Lambda$. Trilling; "OMAE Operating Experience", Nucleunics, 17, No. 11, pp 113-117 (November 1959).

9. R. E. Wyant, The Effect of Nuclear Radiation on Organic Heat-Transfer Materials, REIC-Memo-13 (February 28, 1959).

10. P. W. Solomon, Polyphenyl Analys is, IDO report to be published.

11. Organic Coolant Reactor Program Quarterly Report, 4th Qtr 1961, IDO16761 , p 25 (1962).

12. L. Friedman, Microfilm 60-1181, Thesis, Ohio State Univ. (1959), issued by University Microfilm, Inc., Ann Arbor, Michigan.

13. W. W. West, The Analys is of Polphenyl Radiolysis Products by Gas Chromatography and Other Methods, TID-17508 (October 22, 1962).

14. Organic Coolant Reactor Program Quarterly Report, 4th Qtr 1961, IDO16761, p 24 (1962).

15. Organic Coolant Reactor Program Quarterly Report, 3rd Qtr 1961, IDO16734, p 27 (1961).

16. P. S. Shantarovich, I. A. Shliaphikova, Polymerization Kinetics of Hydrocarbons with Conjugated Bonds II. Polymerization of Phenylacetylene and the Paramagnetic Properties of the Polymer, SCL-T-435 (1961). 


\section{PHILLIPS PETROLEUM COMPANY

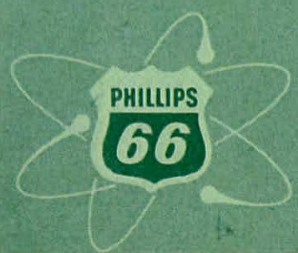

ATOMIC ENERGY DIVISION 